Lilian Ribeiro Caldas Ratto

Prevalência da Comorbidade entre Transtornos Mentais Graves e Transtornos Devido ao Uso de Substâncias Psicoativas em São Paulo, Brasil.

Dissertação apresentada à Faculdade de Medicina de São Paulo para obtenção do título de Mestre em Medicina

São Paulo

2000 
Lilian Ribeiro Caldas Ratto

\section{Prevalência da Comorbidade entre Transtornos Mentais Graves e Transtornos Devido ao Uso de Substâncias Psicoativas em São Paulo, Brasil.}

Dissertação apresentada à Faculdade de Medicina de São Paulo para obtenção do título de Mestre em Medicina

Área de concentração: Medicina Preventiva Orientador: Prof. Dr. Paulo Rossi Menezes

São Paulo 2000 
À DEUS, pela vida e pela minha profissão.

Aos meus pais, Janemary e Flavio e irmão Flavio, pelo apoio e incentivo contínuos.

À memória de meu amado primo, João Ribeiro Caldas Neto. 


\section{AGRADECIMENTOS}

Ao Prof. Dr. Paulo Rossi Menezes, orientador competente, dedicado e sempre disponível, agradeço por sua amizade e confiança.

Ao Prof. Dr. Eduardo Iacoponi, pela inspiração acadêmica, por seu incentivo e apoio à minha formação científica e clínica, e pelo respeito ao meu trabalho.

Ao Prof. Dr. Ronaldo Laranjeira, pelo acompanhamento atencioso, interessado e enriquecedor à minha formação e a este trabalho.

Aos colegas Ana Cristina Belizia Schlithler, Ana Paula D’Ambrosio, Andreia Nascimento, Flavio Neves Soares, Luciana Ferraz, Renata D. Galon Sommerman e Rosângela Gomes de Souza que competentemente participaram deste trabalho e o tornaram mais agradável e bem humorado.

Ao Departamento de Medicina Preventiva da Faculdade de Medicina da USP, pela oportunidade de admirar novos horizontes.

Aos colegas do Departamento de Saúde Mental da Santa Casa de Misericórdia de São Paulo pelo incentivo e amizade.

A Dra. Beatriz Carlini-Cotrim e ao Dr. Nelson Gouveia pelas discussões e sugestões atenciosas e pertinentes na aula de qualificação.

Aos pacientes que desinteressadamente participaram desta pesquisa, e aos que pacientemente me acompanharam nesta jornada.

À CAPES pela bolsa de mestrado e à FAPESP pelo Auxílio à Pesquisa (Processo $n^{\circ}$ 96/10077-3). 


\section{SUMÁRIO}

\section{LISTA DE TABELAS}

RESUMO

SUMMARY

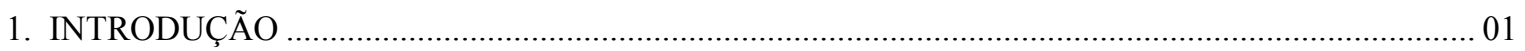

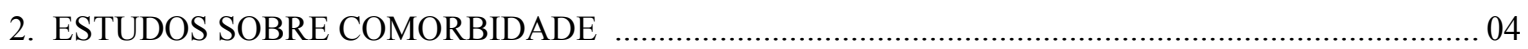

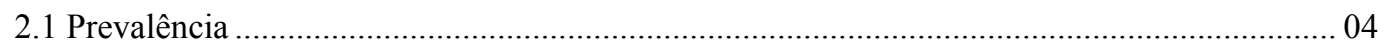

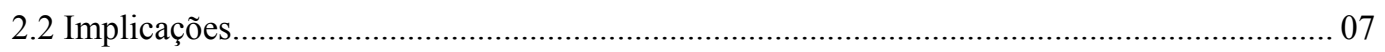

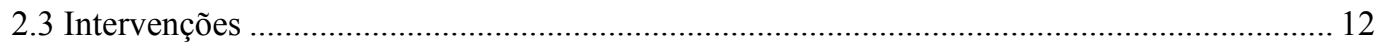

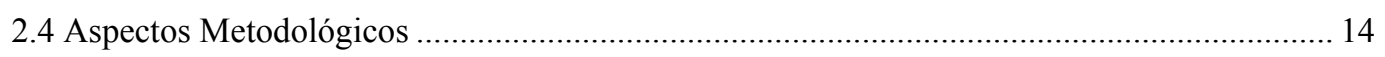

2.5 Definição dos transtornos mentais graves ............................................................................. 17

2.6 Definição de dependência a drogas psicoativas e abuso/uso nocivo

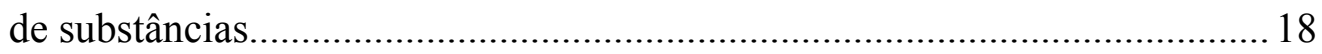

2.7 Definição de comorbidade.................................................................................................. 18

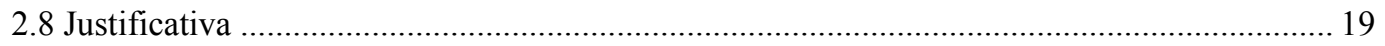

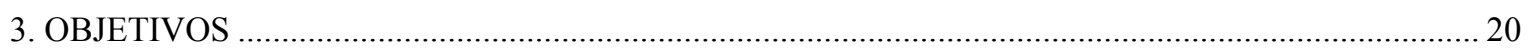

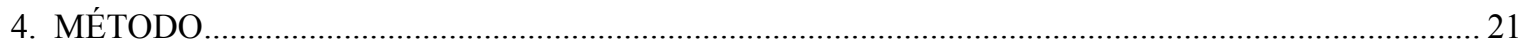

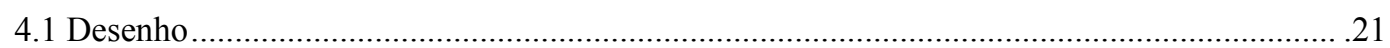

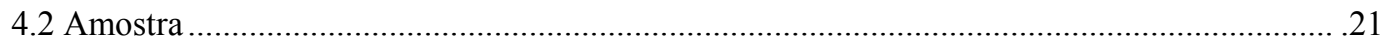

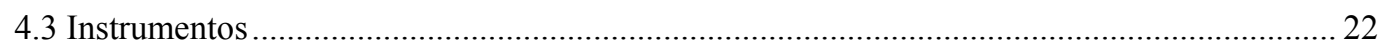

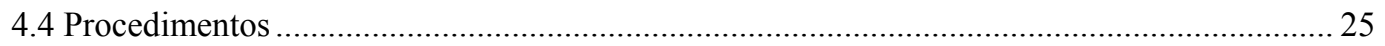

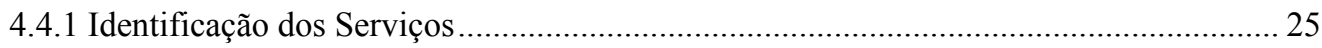


4.4.2 Identificação dos sujeitos elegíveis

4.4.3 Treinamento e Estudo Piloto ........................................................................... 28

4.4.4 Entrevistas com pacientes e informantes ........................................................... 29

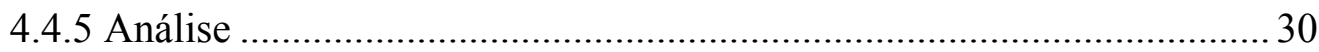

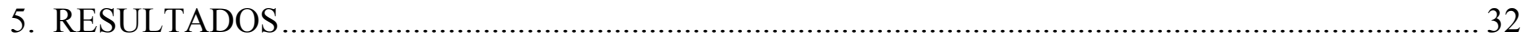

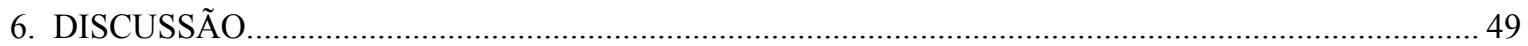

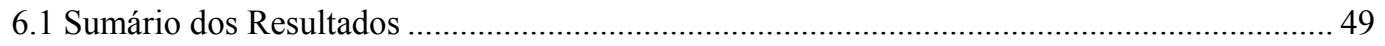

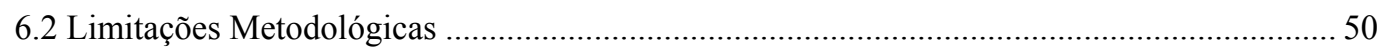

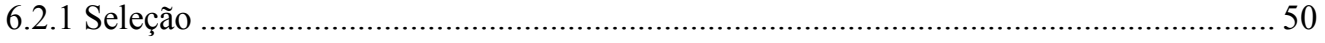

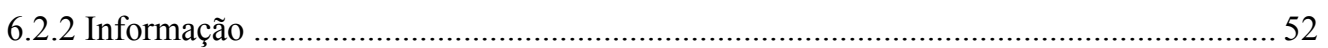

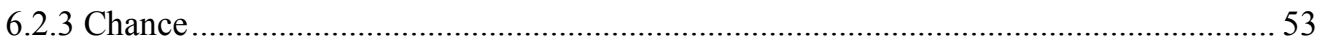

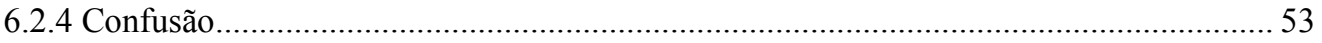

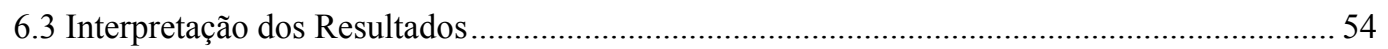

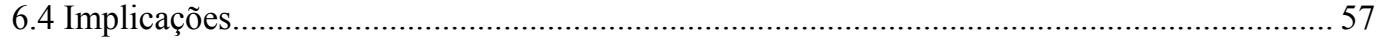

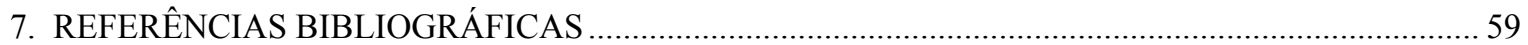

8. APÊNDICES 


\section{LISTAS DE TABELAS}

TABELA 1: Entrevistas realizadas e razões para não realização de Entrevistas

TABELA 2: Características sócio-demográficas da amostra.................................................................. 34

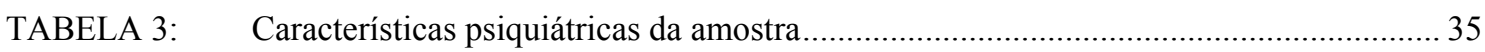

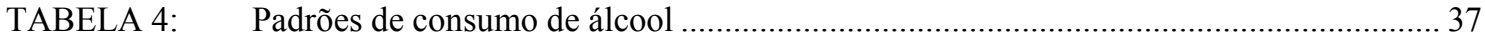

TABELA 5: Padrão de consumo de substâncias psicoativas ilícitas ou fora da prescrição, nos últimos 12 meses

TABELA 6: Associações entre características dos indivíduos e abuso de álcool 42

TABELA 7: $\quad$ Associações entre características dos indivíduos e abuso de substâncias psicoativas.... 44

TABELA 8: Associações entre características dos indivíduos e abuso de álcool e substâncias psicoativas 46 


\section{RESUMO}

RATTO, Lilian Ribeiro Caldas. Prevalência da comorbidade entre transtornos mentais graves e transtornos devido ao uso de substâncias psicoativas em São Paulo, Brasil. São Paulo, 2000. Dissertação (Mestrado) Faculdade de Medicina, Universidade de São Paulo.

OBJETIVOS: O presente estudo visou estimar a prevalência da comorbidade entre transtornos mentais graves e o abuso de substâncias psicoativas, e estudar os fatores associados a essa comorbidade, em pacientes com transtornos mentais graves residentes em São Paulo.

MÉTODO: O estudo teve desenho de corte transversal. Vinte serviços de saúde mental (emergências, hospitais psiquiátricos e ambulatórios) foram pesquisados, a fim de identificar todos os pacientes com idade entre 18 e 65 anos, com diagnóstico clínico de transtorno mental grave, que fossem residentes em um dos 7 distritos administrativos escolhidos para o estudo e que tiveram ao menos um contato com o serviço de saúde no período entre 1/9/1997 e 30/11/1997. Os pacientes incluídos foram avaliados quanto a sintomas psiquiátricos, ajustamento social, uso de álcool e uso de substâncias psicoativas, utilizando-se instrumentos padronizados.

RESULTADOS: Dos 620 pacientes identificados, 404 foram aleatoriamente selecionados para serem entrevistados. Foi possível entrevistar diretamente 192 $(47,9 \%)$ indivíduos. A prevalência de comorbidade nos últimos 12 meses foi de 10,4\% (I.C. 95\%: 6.5 a 15.6), sendo 7,3\% para abuso de álcool e 4,7\% para abuso de drogas ilícitas, e mostrou-se maior entre homens, entre migrantes, entre indivíduos separados/divorciados, em indivíduos com 12 ou mais anos de escolaridade, e em indivíduos com o diagnóstico de transtornos do espectro da esquizofrenia. A presença de sintomas negativos de esquizofrenia foi significativamente menor entre os indivíduos que receberam o diagnóstico de abuso de substâncias psicoativas.

CONCLUSÃO: Os resultados deste estudo sugerem que na população estudada a prevalência de transtornos decorrentes do uso de álcool e outras drogas é mais baixa do que as prevalências encontradas em outros estudos, realizados nos EUA e Europa. Essa discrepância de resultados pode ser devida a diversos fatores, incluindo o consumo de substâncias pela população geral na qual estão os sujeitos investigados, o ambiente social onde esses sujeito vivem e aspectos culturais relacionados ao consumo de substâncias. 


\section{SUMMARY}

RATTO, Lilian Ribeiro Caldas. Prevalence of comorbidity between severe mental illnesses and substance use disorders in São Paulo, Brazil. São Paulo, 2000. Dissertação (Mestrado) Faculdade de Medicina, Universidade de São Paulo.

OBJECTIVES: To investigate the prevalence of substance use disorders among patients with severe mental illnesses in São Paulo, Brazil, and to study factors associated with such comorbidity.

METHOD: The study had a cross-sectional design. Twenty mental health services (emergency, inpatient and outpatient services) were scrutinized to identify all patients aged 18 to 65 years old, with a clinical diagnosis of severe mental illness, who were resident in one of 7 administrative districts chosen for the study, and had had at least one contact with such services between $1^{\text {st }}$ September and $30^{\text {th }}$ November 1997. Assessments included psychiatric symptoms, social adjustment, and patterns of alcohol and drug use, using standardized instruments. RESULTS: Out of 620 patients identified, 404 were randomly selected to be interviewed. One hundred and ninety two patients $(47.9 \%)$ were directly interviewed. The prevalence of comorbidity was 10,4\% (95\% CI: 6.5 to 15.6$)$, being 7,3\% for alcohol abuse and 4,7\% for drug abuse, and was higher among male subjects migrants, single or separated individuals, those with 12 or more years of education, and among those with schizophrenia-like disorders. Presence of negative symptoms was associated with lower prevalence of comorbidity.

CONCLUSIONS: Results of the present study suggest that the prevalence of dual diagnosis in São Paulo is lower than those found in previous studies, carried out in the USA and Europe. Such discrepancy may be due to several factors, including population patterns of substance use, the social environment where patients live, and cultural issues related to the use of alcohol. 


\section{INTRODUÇÃO}

Investigações nos Estados Unidos da América (EUA) e Europa têm indicado que pacientes com transtornos psiquiátricos graves, como esquizofrenia e transtornos afetivos bipolares, apresentam altas taxas de comorbidade para transtornos mentais devido ao uso de substâncias psicoativas. As prevalências encontradas variam de $20 \%$ a $75 \%$ das amostras investigadas (BARBEE et al. 1989; REGIER et al. 1988; DRAKE et al. 1989; DRAKE; WALLACH 1993; DUKE et al. 1994). Essa ampla variação tem sido atribuída a diferenças no tipo de serviços que deram origem às amostras, nos métodos de avaliação utilizados, nas definições de transtornos devido ao uso de substâncias, em variações nas características sóciodemográficas das amostras, variações na disponibilidade de drogas ilícitas na comunidade e conforme a região geográfica estudada (EL GUEBALY, 1990).

Diversos estudos têm relatado efeitos negativos do abuso ou dependência de substâncias psicoativas em pessoas com transtornos mentais graves. A evolução clínica e social destes pacientes pode ser pior que a observada em pessoas com transtornos mentais graves sem tal comorbidade, (DUKE et al. 1994; MENEZES et al. 1996). Estudos mostram evidências de que indivíduos com a referida comorbidade utilizam serviços de emergência psiquiátrica e são internados mais freqüentemente, permanecem maior tempo no hospital e apresentam mais episódios de comportamentos agressivos quando internados (MENEZES et al. 1996; YESAVAGE; ZARCONE, 1993). Também têm sido descritas maiores taxas de detenção por atos ilegais e de falta de moradia em pacientes com a comorbidade em questão (TESSLER; DENNIS, 1989). A maior utilização de serviços psiquiátricos está associada a um maior custo de tratamento para estes pacientes (BARTELS et al. 1993) e há evidências de que exista um impacto econômico nas famílias dos mesmos (CLARK; DRAKE, 1994). 
A incidência de comorbidade de abuso ou dependência de substâncias e transtornos mentais graves parece estar aumentando (CUFFEL, 1997). Este fenômeno tem sido atribuído ao aumento e disponibilidade de álcool e drogas na população geral, e ao processo de desinstitucionalização e priorização de cuidados de saúde para pacientes com transtornos psiquiátricos graves na comunidade, fatores que provavelmente tornam mais fácil o acesso a álcool e drogas por parte de tais pacientes, em relação ao acesso que era possível para aqueles pacientes que eram mantidos permanentemente em hospitais psiquiátricos asilares. Alguns investigadores têm sugerido que pessoas com transtornos mentais graves podem utilizar álcool e drogas como uma forma de auto-medicação, numa tentativa de reduzir o desconforto causado por sintomas como ansiedade e depressão ou por efeitos colaterais dos medicamentos psicotrópicos (SCHEIER; SIRIS, 1987).

Estudos realizados nos EUA e Europa têm concluído que tanto os serviços psiquiátricos voltados ao tratamento de pacientes com transtornos mentais graves, como os serviços de atendimento a usuários de drogas, não conseguem abordar adequadamente pacientes com a referida comorbidade (JOHNSON, 1997). Os técnicos que trabalham em serviços de psiquiatria geral, têm muitas vezes, pouca ou nenhuma experiência no manejo de pacientes que abusam de drogas psicoativas. Quando esses pacientes procuram atendimento intoxicados, a equipe tende a se sentir irritada, podendo inclusive, aplicar medidas punitivas ao paciente. Alguns serviços simplesmente não admitem esses pacientes, e problemas com a moradia parecem ser particularmente importantes. Em contra partida, profissionais dos serviços voltados ao atendimento de pacientes dependentes têm pouca segurança e experiência em trabalhar com pacientes psicóticos, e acreditam que o tratamento destes está além de suas possibilidades. Além disso, freqüentemente a abordagem utilizada com dependentes é imprópria ao acompanhamento de pacientes com transtornos mentais graves, principalmente aquelas baseadas na confrontação, onde os limites de tolerância à recaída são muito estreitos e onde o tom emocional das sessões de terapia tendem a ser muito altos. 


\section{Situação no Brasil}

ALMEIDA-FILHO et al. (1997), em estudo epidemiológico de base populacional em três grandes centros brasileiros avaliou a presença de sintomas psiquiátricos em uma população representativa de cada centro, encontrando uma prevalência na vida de $51 \%(+-3,4 \%)$ dos entrevistados na área metropolitana de Brasília, de 43\% (+- 3,5\%) na área metropolitana de Porto Alegre e de cerca de 30\% (+- 3,5\%) na área metropolitana de São Paulo. Os transtornos psicóticos foram diagnosticados pelos critérios do DSM-III-R em cerca de $1 \%$ da população entrevistada em São Paulo e Brasília e em mais de $2 \%$ da população entrevistada em Porto Alegre. O diagnóstico de dependência de álcool pode ser constatado em $5 \%$ da população de Brasília, em 4\% em São Paulo e em 9\% da população de Porto Alegre; problemas com alcoolismo foram detectados em cerca de $15 \%$ da população masculina destas cidades, se constituindo no maior problema de saúde mental encontrado nestas populações.

NOTO; CARLINI, 1995, promoveram um levantamento das internações psiquiátricas hospitalares devido a dependência no período de 1987 a 1993, onde foram analisados dados sobre pacientes internados por quadros de dependência ao álcool e a drogas psicoativas. Apenas 30\%-40\% dos hospitais psiquiátricos cadastrados enviaram os dados, no entanto é possível avaliar que mais de 90\% das internações se deviam ao uso de álcool; entre 1987 e 1991 as internações por problemas com drogas se mantiveram constantes, mas após este período, tiveram importante crescimento. Em 1988, ocorreram 36.188 internações psiquiátricas ligadas ao abuso de álcool, sendo 28.897 em indivíduos maiores de 30 anos de idade e 3.062 pelo uso de drogas, das quais 2.216 de indivíduos entre 18 e 30 anos. Observou-se um aumento gradativo das internações provocadas pelo uso de cocaína e de drogas do tipo da morfina e uma diminuição das internações provocadas pelo uso de Cannabis e anfetaminas. Foram claras as diferenças regionais encontradas elo estudo, e que não se devem apenas a presença de um maior número de hospitais psiquiátricos nas regiões sul e sudeste do país, indicando que essas evidencias devem ser consideradas na elaboração de programas e políticas de saúde. 


\section{ESTUDOS SOBRE COMORBIDADE}

\subsection{Prevalência}

A prevalência de transtornos por uso de álcool e substâncias psicoativas é bastante variável, conforme as características das amostras utilizada nos diferentes estudos.

BARBEE et al. (1989), usando o "Diagnostic Interview Schedule", encontraram uma prevalência durante a vida de $60 \%$ para abuso de substâncias, em 53 pacientes com esquizofrenia, que foram atendidos em um serviço de intervenção em crise de uma emergência psiquiátrica, em um hospital geral universitário de New Orleans.

DRAKE et al. (1989) investigaram uma amostra de 115 pessoas com esquizofrenia que após terem sido submetidos a uma internação psiquiátrica, participavam de um programa ambulatorial de atendimento a pacientes psicóticos, em Nova Inglaterra, EUA. Quarenta e cinco por cento dos pacientes relataram consumir álcool, e 22\% preenchiam os critérios do DSM-III-R ("Diagnostic and Statistical Manual of Mental Disorders", terceira edição, revisada) para abuso ou dependência de álcool.

DRAKE; WALLACH (1993) encontram uma prevalência de 14\% de uso moderado de álcool por pacientes com esquizofrenia, em área rural, e em uma área urbana de 24\% numa amostra de pacientes que recebem atendimento ambulatorial; em um estudo de "follow-up" (quatro e sete anos respectivamente), desses indivíduos, 24,4\% haviam desenvolvido quadro de dependência ao álcool e $55,6 \%$ mantiveram-se abstinentes neste período.

Um estudo em Munich, realizado por SOYKA et al. (1990), com 630 pacientes com diagnóstico de esquizofrenia, avaliou a prevalência de 
abuso/dependência de drogas ilegais, durante a vida, e nos últimos três meses em pacientes internados em dois hospitais psiquiátricos: Psychiatric Hospital of the University of Munich (grupo 1) e Mental State Hospital Haar/Munich (grupo 2), sendo a característica dos pacientes do grupo 2, a de serem mais cronicamente comprometidos. As prevalências encontradas para o abuso/dependência de qualquer substância foi de $21,8 \%$ na vida e $21,3 \%$ nos últimos 3 meses para o grupo 1 e de $42,9 \%$ na vida e $29 \%$ nos últimos 3 meses para o grupo 2 . A prevalência na vida, para o uso de álcool e drogas ilegais foi de $17,4 \%$ e 5,5\%, respectivamente, no grupo 1 e $34,6 \%$ e 14,3\% no grupo 2 e nos últimos 3 meses de 17,4\% e 5,5\% no grupo 1 e $20,8 \%$ e $11,4 \%$ no grupo 2; para quadros apenas de dependência, as prevalências encontradas foram bastante menores. O grupo 1 apresentou uma prevalência para dependência de álcool, na vida e nos últimos 3 meses de $4,9 \%$ e para dependência de drogas ilegais de 1,1\%. O grupo 2 apresentou uma prevalência de dependência de álcool de 13,4\% na vida e 7,6\% nos últimos 3 meses e de drogas ilegais de $6,7 \%$ na vida e $5,1 \%$ nos últimos 3 meses.

VERDOUX et al. (1996) em um estudo comparativo entre pacientes com transtornos bipolares, esquizofrênicos e esquizoafetivos, realizado pela Universidade de Bordeaux, encontrou uma prevalência de uso de substâncias ilícitas nos últimos 6 meses em 17,5\% em pacientes com transtornos afetivos, em 7,9\% dos pacientes com esquizofrenia e em 21,4\% dos pacientes com diagnóstico de transtorno esquizoafetivo, e 47,8\% têm em sua história o diagnóstico de abuso ou dependência de, pelo menos duas, drogas ilícitas.

DUKE et al. (1994), em estudo epidemiológico de base populacional, encontraram uma prevalência de $22 \%$ para problemas com uso de álcool durante a vida, após avaliar, com questionários, 271 pacientes esquizofrênicos, em South Westminster, Londres. Em outro estudo recentemente realizado em Londres, a partir de informações obtidas utilizando-se de entrevistas, com 171 pacientes com transtornos mentais graves que tiveram algum contato com os serviços de saúde mental de uma região definida no sul de Londres, a prevalência estimada para problemas com uso de substâncias psicoativas (álcool e drogas ilícitas) foi de 36\%, 
durante o ano anterior à entrevista, de 31,6\% para problemas relacionados ao uso de álcool e de 15,8\% ao uso de drogas (MENEZES et al. 1996).

Em um estudo epidemiológico de base populacional realizado nos EUA, foram analisados dados de 20.291 (REGIER et al. 1988; REGIER et al. 1990). Foi encontrada uma prevalência de abuso ou dependência de substâncias de $29 \%$ $(\mathrm{OR} 2,7)$ entre pessoas com qualquer transtorno mental enquanto a prevalência de abuso ou dependência de substâncias em pessoas sem outro transtorno mental foi de $13 \%$. Essa comorbidade entre esquizofrênicos foi de $29 \%$, e entre pessoas com transtornos afetivos bipolares foi de $32 \%$. Os autores descrevem ainda que $50 \%$ dos indivíduos com transtornos mentais graves desenvolvem desordens relacionadas ao uso de álcool ou outras drogas psicoativas em algum período de suas vidas.

Segundo estudo epidemiológico de base populacional de KESSLER et al. (1994), que avaliou pessoas de 15 a 54 anos de idade, há indicações de que, nos EUA, a prevalência de transtornos por uso de substâncias é maior na população de pacientes com transtornos mentais graves, do que na população geral.

Segundo BOYD et al. (1984), a partir de estudos também de base populacional, nos EUA usando informações do National Institute of Mental Health Diagnostic Interview Schedule, com uma amostra de 11.519 indivíduos, o abuso de substâncias psicoativas é a comorbidade psiquiátrica mais prevalente associada a esquizofrenia.

CUFFEL, (1992) em sua revisão bibliográfica sobre a estimativa de prevalência de esquizofrenia e abuso de substâncias e fatores relacionados, sugere que o abuso de álcool entre pacientes esquizofrênicos é comparável ou maior do que o encontrado na população geral, mas que alguns estudos, como os de ALTERMAN et al. (1981) encontraram prevalências menores do que a encontrada na população geral. Sugere ainda que o abuso de estimulantes é maior na população de pacientes com esquizofrenia, mas atenta para um fato importante que até então parecia ser despercebido, o de que a prevalência de abuso de drogas e álcool vem aumentando desde a década de 60 . 


\subsection{Implicações}

Diversos estudos discutem as implicações clínicas e sociais do abuso de substâncias por pacientes portadores de transtornos mentais graves. Maiores taxas de recaída, reinternações, detenção por atos ilegais, tentativas de suicídio, heteroagressividade, falta de moradia, maiores gastos com o tratamento e maior utilização de serviços médicos são descritas para esta população e demonstram uma pior evolução clínica e social

DRAKE et al. (1991), estudou 75 pacientes com esquizofrenia que abusam de álcool, quanto a suas experiências subjetivas; cerca de $70 \%$ relataram melhora de ansiedade e tensão quando usam álcool, $62,1 \%$ efeitos positivos no humor, 59,1\% melhora nos sentimentos apatia e anedonia, e 56,1\%, melhora de distúrbios do sono; relatavam melhora na ansiedade, disforia insônia e sintomas não psicóticos, sentidos como desprazeirosos.

SERPER et al. (1995) avaliou 37 pacientes com diagnóstico de esquizofrenia que deram entrada num serviço de emergência psiquiátrica, onde 15 eram abusadores de cocaína e 22 não abusadores, segundo os critérios do DSM-III$\mathrm{R}$; feitas 2 avaliações, a primeira no momento da admissão e a segunda 4 semanas após a internação, encontrou, em pacientes com esquizofrenia que abusam de cocaína, significativamente menos sintomas negativos do que em pacientes esquizofrênicos que procuraram a emergência e não abusam desta droga, tanto quando intoxicados, como após 4 semanas de abstinência da droga Não é possível ainda determinar se as propriedades psicoestimulantes da cocaína causam temporariamente um decréscimo destes sintomas ou se estes pacientes, por terem menos sintomas negativos podem então procurar drogas ilícitas, e representariam assim, um sub-grupo de pacientes com um melhor funcionamento social. RIES et al. (1994) descreve em um estudo feito em uma enfermaria só com pacientes internados voluntariamente, que indivíduos com transtornos mentais graves, (porém não exclusivamente esquizofrenia, transtornos afetivos e esquizoafetivos) que não são usuários de álcool e drogas ilícitas, foram internados apresentando mais sintomas psicóticos e confusionais que pacientes com a comorbidade estudada. Porém, os 
pacientes com a comorbidade apresentavam mais sintomas depressivos e ideação suicida que os não abusadores de drogas.

CUFFEL et al. (1995) sugerem, com dados dos indivíduos do "Epidemiological Catchment Area", com diagnóstico de esquizofrenia e transtorno esquizofreniforme que pacientes com abuso de álcool ou Cannabis e aqueles que abusam de múltiplas drogas psicoativas apresentam mais sintomas depressivos, mas não mais sintomas psicóticos que os não abusadores de substâncias.

Alguns autores sugerem que é importante a diferenciação entre pacientes com transtornos mentais graves que abusam de drogas psicoativas daqueles que apresentam quadros de dependência a essas drogas, uma vez que parece ser bastante diferente a evolução destes indivíduos. Segundo BARTELS et al. (1995) parece haver uma tendência maior ao abandono do uso de álcool e drogas entre os pacientes que somente abusam delas, do que naqueles que apresentam quadros de dependência. Isto, mesmo apesar de haver evidências que a prevalência de transtornos mentais por uso de substâncias psicoativas, não é muito variável entre uma população de pacientes com esquizofrenia.

CUFFEL et al. (1995) sugerem ainda, em estudo que analisou dados dos indivíduos captados do "Epidemiological Catchment Area", com diagnóstico de esquizofrenia e transtorno esquizofreniforme que o uso de uma droga qualquer, seja álcool, Cannabis ou outra, predispõe o indivíduo ao abuso de um maior número de drogas.

No estudo de DUKE et al. (1994), com 271 pacientes esquizofrênicos, em South Westminster, Londres, pacientes que abusavam de álcool tinham significantemente menor tempo de doença, e maiores taxas de hostilidade, ansiedade, depressão e alucinações.

SANGUINETI; SAMUEL (1993) encontraram em seu estudo com 401 pacientes internados involuntariamente em uma unidade de tratamento intensivo, que ao serem admitidos eram submetidos a exames toxicológicos de urina, que pacientes com esquizofrenia e que apresentavam teste positivo para a presença de 
substâncias psicoativas tinham menos sintomas paranóides, menos transtornos do pensamento, menos depressão ansiosa e também menos agitação do que pacientes com esquizofrenia e teste negativo. Pacientes com diagnóstico de transtornos afetivos e teste positivo, apresentavam maiores taxas de sintomas paranóides, depressão ansiosa, hostilidade e agitação, que os com teste negativo.

OSHER et al. (1994) avaliaram 75 pacientes ambulatoriais com o diagnóstico de esquizofrenia ou transtorno esquizoafetivo, segundo os critérios do DSM-III-R, acompanhados em um centro de saúde mental comunitário de uma região rural de New England, quanto ao uso de álcool. Encontraram maiores taxas de re-hospitalização, de abuso de mais de uma droga, de negação da doença mental, e não aderência a medicação. Encontrou também uma maior tendência, nesses pacientes, a apresentar problemas com moradia.

Há evidências de que indivíduos com a referida comorbidade utilizam serviços de emergência psiquiátrica e são internados mais freqüentemente, permanecem maior tempo no hospital e apresentam mais episódios de comportamentos agressivos quando internados. MENEZES et al. (1996) avaliaram 171 pacientes que entraram em contato com algum serviço psiquiátrico em uma região delimitada do sul de Londres, quanto ao tempo de internação destes indivíduos, encontrando que pacientes com a referida comorbidade permaneciam até duas vezes mais dias no hospital, nos últimos dois anos, do que pacientes sem a comorbidade, com uma diferença de 23,3 dias (IC 95\%: 3,8-48,7).

YESAVAGE; ZARCONE (1993) avaliaram a historia de uso de álcool e drogas de 85 pacientes com diagnóstico de esquizofrenia internados numa enfermaria psiquiátrica e sua periculosidade enquanto internados (agressões físicas e verbais e episódios de exclusão e restrição). Encontraram que episódios de agressividade estão relacionados ao abuso de drogas, a episódios de "blackout" anteriores e aos períodos de intoxicação por álcool ou drogas.

SULLIVAN et al. (1998) concluem em um estudo caso-controle sobre re-hospitalização, com 202 pacientes com diagnóstico de esquizofrenia do "Mississippi State Hospital” e outros 10 serviços comunitários de saúde mental de 
região, ser o abuso de álcool, um dos mais importantes fatores que levam indivíduos com graves doenças mentais de volta para o hospital.

GUPTA et al. (1996) em um estudo retrospectivo com pacientes masculinos com esquizofrenia, seguidos por pelo menos 2 anos na "Omaha V.A. Medical Center Decanoate Clinic", encontraram resultado semelhante, onde o abuso atual de qualquer droga psicoativa aumenta as chances de reinternação destes pacientes, propondo ainda que isso acorra a despeito da aderência ou não a medicação psiquiátrica.

A maior utilização de serviços psiquiátricos está associada a um maior custo de tratamento destes pacientes. BARTELS et al. (1993) analisou dados de 74 pacientes com diagnóstico de esquizofrenia ou transtorno esquizoafetivo, separandoos em três grupos: os que atualmente abusam de álcool ou drogas, os que já fizeram abuso, mas estão abstinentes e pacientes que jamais fizeram abuso de substâncias. Encontraram que pacientes que abusam atualmente de substâncias psicoativas utilizam significantemente mais os serviços de institucionalização, internações psiquiátricas, duas vezes mais os serviços de emergência, chegam a permanecer até quarenta vezes mais dias internados, com um custo ao menos seis vezes maior do que os pacientes que não abusam de substâncias. A utilização de serviços ambulatoriais e de reabilitação não se mostrou maior ou mais dispendioso para este grupo.

Há evidências de que exista um impacto econômico nas famílias dos mesmos (CLARK, 1992), onde se utiliza $16 \%$ da renda familiar para a manutenção do paciente, contra $6 \%$ gastos para a manutenção de um adulto sem uma doença crônica. CLARK (1992), estudou 119 famílias de adultos com uma doença mental grave e uso de substâncias e 127 famílias de adultos sem doenças crônicas, que moravam numa mesma região de New Hampshire e encontrou indícios de que não existem apenas maiores gastos com dinheiro, mas também em tempo despendido em cuidados com o familiar doente.

MCCRONE et al. (2000) analisou dados de 27 pacientes com diagnóstico de comorbidade (transtorno mental grave e abuso de substâncias) em comparação a um grupo controle com 64 indivíduos, moradoras da região sul de 
Londres, que fazem tratamento psiquiátrico, quanto ao uso de serviços e custos, concluindo que pacientes com a referida comorbidade utilizam mais os serviços psiquiátricos de emergência e internação e representam um maior gasto a estes serviços psiquiátricos, com uma diferença de £1362, e de £1360 em gasto com outros serviços.

Também têm sido descritas maiores taxas de detenção por atos ilegais e de falta de moradia em pacientes com a comorbidade em questão. BARTELS et al. (1993) descreve em seu estudo, com 74 pacientes tratados num centro de saúde mental comunitário numa região rural em New England, que os pacientes com esquizofrenia ou transtorno esquizoafetivo que abusam ou são dependentes de drogas psicoativas, foram responsáveis por todos os casos de detenção e por grande parte das internações psiquiátricas nos pacientes estudados.

SOYKA et al. (1992) em seu estudo com 630 pacientes psiquiátricos internados em duas enfermarias psiquiátricas, descrevem taxas de falta de moradia entre $37,5 \%$ e $41,5 \%$ para pacientes com comorbidade e entre $19,5 \%$ e $21,4 \%$ para os sem a comorbidade. DRAKE et al. (1991) em uma revisão sobre comorbidade e pacientes moradores de rua, afirma que cerca de $10 \%$ a $20 \%$ dos indivíduos sem moradia são portadores de um transtorno mental e fazem abuso de substâncias psicoativas.

CUFFEL et al. (1994) em um estudo sobre violência, feito com 103 pacientes ambulatoriais em tratamento no San Francisco General Hospital (San Francisco, CA), que têm o diagnóstico de esquizofrenia, transtorno esquizoafetivo ou transtornos esquizofreniformes, encontraram evidências de que certas substâncias, como estimulantes, opiáceos e alucinógenos, podem predispor indivíduos com esquizofrenia a episódios de violência; estes, apresentaram um Odds de violência 12 vezes maior que os indivíduos com esquizofrenia que não abusam de qualquer substância. Indivíduos que abusavam de álcool ou Cannabis não apresentavam tal risco elevado de violência.

SCOTT et al. (1998) a partir de informações obtidas utilizando-se de entrevistas, com pacientes com transtornos mentais graves que tiveram algum 
contato com os serviços de saúde mental de uma região definida no sul de Londres, avaliaram 27 pacientes com diagnóstico de transtorno mental grave (esquizofrenia, transtorno bipolar ou outro transtorno psicótico) e de abuso ou dependência de substâncias psicoativas e compararam a um grupo de 65 pacientes apenas com o diagnóstico de transtorno mental grave, para estimar se pacientes com comorbidade apresentam mais comportamentos violentos e detenção por atos ilegais. Encontraram que pacientes com a referida comorbidade apresentam maior chance de terem cometido qualquer ato de violência durante a vida (OR: 5,5), inclusive de atos de violência não ligados ao uso de substâncias (OR: 6,0), tiveram mais episódios agressivos nos últimos 5 anos (OR: 11,4) e também nos últimos 2 anos, e foram detidos mais vezes (OR: 5,1); apresentaram mais sintomas de hostilidade nas últimas 2 semanas (OR: 6,5) e mais comportamentos violentos moderadamente graves, inclusive relatados pelos seus profissionais de referência.

SOYKA et al. (1992) encontraram maiores taxas de tentativa de suicídio entre pacientes esquizofrênicos que abusam de álcool ou outras drogas, do que em pacientes esquizofrênicos sem comorbidade, em estudo desenvolvido em Munich, com 630 pacientes de dois hospitais psiquiátricos, que foram divididos em dois grupos. Em um dos grupos 30\% dos pacientes com comorbidade haviam tentado suicídio enquanto $13,2 \%$ dos pacientes sem a comorbidade o haviam tentado. No segundo grupo, composto de pacientes considerados mais cronicamente afetados, $50 \%$ dos pacientes com a comorbidade tiveram tentativas, e 37,3\% dos sem comorbidade também o tentaram.

\subsection{Intervenções}

Os técnicos que trabalham em serviços de psiquiatria geral, têm muitas vezes, pouca ou nenhuma experiência no manejo de pacientes que abusam de drogas psicoativas. Quando esses pacientes procuram atendimento intoxicados, os técnicos envolvidos com o atendimento tendem a se sentirem irritados e a podem aplicar medidas punitivas ao paciente (JOHNSON, 1997). Alguns serviços simplesmente não admitem esses pacientes, e problemas com a moradia parecem ser particularmente 
importantes. Em contra partida, serviços voltados ao atendimento de pacientes dependentes têm pouca segurança e experiência em trabalhar com pacientes psicóticos, e acreditam que o tratamento destes está além de suas possibilidades. Há ainda, alguns serviços voltados ao dependente que são bastante impróprios ao acompanhamento de pacientes com transtornos mentais graves, principalmente aqueles que usam a confrontação, onde os limites de tolerância à recaída são muito estreitos e onde o tom emocional das sessões de terapia tendem a ser muito altos. Por esta razão, têm sido propostos programas específicos para estes pacientes, que permitam às equipes de saúde mental desenvolver formas efetivas de lidar com os mesmos, visando conscientizá-los da necessidade de se tornarem abstinentes, melhorar sua aderência ao tratamento e reorganizar suas redes sociais (JERRELL; RIDGELY, 1995). Estes novos serviços são mantidos sob constante avaliação, e são bastante diferentes entre si. Alguns incluem unidades especializadas, inclusive quanto a moradia para estes pacientes; outros, o atendimento em unidades de psiquiatria geral, está associada ao modelo dos 12-passos do Alcóolicos Anônimos (MINKOFF, 1989; GALANTER et al. 1994). Diversos estudo procuram também encontrar medicamentos mais específicos, ou com os quais pacientes com a referida comorbidade apresentem melhora significativa, tantos dos transtornos psicóticos, como do abuso de substâncias psicoativas. Alguns poucos programas têm ainda se preocupado em oferecer tratamento para pacientes com a comorbidade e que são moradores de rua.

LEY, et al. (1999), em revisão para a Cochrane sobre a efetividade dos programas de tratamento para pessoas com o duplo diagnóstico não encontrou nenhuma evidência que apoie uma vantagem de qualquer tipo de tratamento específico para a população que apresenta a comorbidade, e nenhum dos programas se mostrou superior ao outro. No entanto, apenas 6 estudos foram considerados relevantes, dos quais 4 eram constituídos de amostras pequenas No geral, a qualidade dos dados e do desenho dos estudos não eram altas e dados clinicamente importantes como recaídas da doença psiquiátrica, violência, satisfação com o tratamento, funcionamento social, situação ocupacional, não foram avaliados pelos serviços. 


\subsection{Aspectos metodológicos}

São diversas as limitações a que estão sujeitos os estudos de pacientes com transtornos mentais graves e transtornos por uso de substâncias psicoativas. As mais importantes são as relacionadas aos diagnósticos do transtorno mental grave e de abuso ou dependência de substâncias, às características da amostra investigada e à informações sobre o padrão de consumo de substâncias psicoativas, particularmente de drogas ilícitas.

Existe uma dificuldade em diferenciar entre a presença de comorbidade (abuso de substâncias psicoativas e transtornos mentais graves) e quadros psicóticos devido ao efeito destas substâncias. Muitas drogas podem produzir sintomas psicóticos durante a intoxicação e mesmo durante os quadros de abstinência a elas, como é o caso dos alucinógenos e do álcool, respectivamente. Quadros de psicose induzida por drogas psicoativas são bastante confundidos com quadros de esquizofrenia e mesmo com quadros maniformes, sendo muitas vezes impossível o diagnóstico sem um longo período de avaliação do paciente, estando este, abstinente do uso destas substâncias. Também ainda não é claro o efeito destas substâncias na apresentação dos sintomas em pacientes com transtornos mentais graves, não sendo possível estabelecer a real influência das drogas psicoativas sobre a psicopatologia: alucinações experimentadas por dependentes de álcool podem não diferir significativamente das alucinações experimentadas por pacientes esquizofrênicos (SALLOUM et al. 1991).

O diagnóstico de abuso e dependência de substâncias psicoativas é particularmente difícil, tanto na população geral como numa população de pacientes com transtornos mentais. O uso de substâncias referido pelo paciente é o método mais utilizado para identificar padrões de uso, complicações decorrentes deste e sintomas relacionados à dependência. São muitos os questionários que têm sido utilizados e que pesquisadores vêm tentando validar também, para o uso com uma população de pacientes com transtornos mentais graves associado ao uso de drogas. Dentre eles "Drug Abuse Screening Test"(DAST) (SKINNER, 1982)), "Michigan Alcoholism Screening Test”(MAST) (SELZER, 1971), “CAGE” ( siglas para “cut- 
down", “annoyed", "guilty" e "eye-opener") (MAYFIELD et al. 1974), "Psychiatric Research Interview for Substance and Mental Disorders"(SCID-AD) (GRANT; TOWLE, 1991), “Addiction Severity Index"(ASI) (MCLELLAN et al. 1992), "Schedules Of Clinical Assessment in Neuropsychiatry" (SCAN) (WHO, 1996) (RACHBEISEL 1999). A escolha da entrevista a ser utilizada deve se basear nos objetivos do estudo e para isto, existem diferentes instrumentos desenvolvidos para cada tipo de avaliação especifica. Instrumentos de triagem são destinados a identificação de indivíduos que provavelmente apresentam problemas relacionados ao abuso de substâncias; necessitam ter maior sensibilidade que especificidade como “CAGE”, "AUDIT" (“Alcohol Use Disorders Identifications Test"; (BABOR et al. 1992), "MAST”, “DAST”. Instrumentos para diagnóstico permitem um diagnóstico formal e/ou a quantificação dos sintomas, de acordo com os principais sistemas diagnósticos (CID e DSM) como "SCID", "SCAN", "CIDI" ("Composit International Dianostic Interview", (WITTCHEN et al. 1991), "SADD” (“Short Alcohol Dependence Data”, (DAVIDSON; RAISTRICK, 1986), "SADQ” (“Severity Of Alcohol Dependence Questionnarie", (STOCKWELL et al. 1983). Estas são entrevistas mais específicas, que podem ser úteis inclusive para acompanhamento durante o tratamento, por avaliarem também o comprometimento trazido pelo uso de substâncias para a vida do indivíduo, e para estudos epidemiológicos. Alguns estudos mostram uma tendência ao sub-relato do uso de drogas, tanto legais, como o álcool, quanto ilegais; nestas, o fenômeno tende a ser ainda mais acentuado (MIECZKOWSKI et al. 1991). Têm-se usado e recomendado associar às informações obtidas nos questionários padronizados para detecção do uso de drogas, diversas outras fontes de informação e diagnóstico (MIECZKOWSKI et al. 1991; DRAKE; MERCER-MCFADDEN, 1995; SHANER et al. 1993): informações constantes nos prontuários destes pacientes, informações obtidas com profissionais responsáveis pelo tratamento deste, e análise de amostras de urina ou fios de cabelo.

Análises laboratoriais de amostras de urina e fios de cabelo, isoladamente, estimam o uso de substâncias, mas por si, não revelam dados específicos para o diagnóstico de abuso e dependência. SHANER et al. (1993) em estudo conduzido no "Veterans Affairs Psychiatric Hospital", em Los Angeles, com 100 indivíduos com diagnóstico de esquizofrenia consecutivamente admitidos 
naquele serviço, obtiveram um relato de uso de drogas em 16\% dos pacientes, enquanto o teste de urina foi positivo em $31 \%$ deles.

MCPHILLIPS et al. (1996) desenvolvram um estudo onde, além de aplicar questionários, obteveram informações de outras fontes (prontuários, informantes) e aplicaram testes de urina e análise de fios de cabelo em 39 indivíduos com diagnóstico de esquizofrenia. Entre os questionários com o auto-relato e as informações obtidas com os testes de urina, encontrou uma sensibilidade de 17\%, e uma especificidade de 100\%, uma vez que houveram seis relatos de abuso de Cannabis e apenas um teste positivo. O autor julgou que o teste de urina utilizado tinha um ponto de corte bastante conservador, advertiu sobre os riscos de "falsopositivo" quanto pontos de corte mais baixos são utilizados, e sugeriu que métodos mais acurados sejam usados para confirmação. No entanto, os testes utilizando amostras de cabelo se mostraram muito superiores, mostrando que um quarto da amostra havia utilizado anfetaminas nos três meses anteriores, e que $8 \%$ dos indivíduos haviam utilizado cocaína, enquanto nos questionários, apenas um indivíduo havia relatado o uso de estimulantes.

MIECZKOSWSKI et al. (1991) em estudo realizado nos EUA, pelo Instituto de Criminologia, "University of South Florida", com 300 indivíduos sem doença mental franca, detidos pela justiça, voluntários, entrevistados e testados anonimamente, comparou testes de urina e cabelo com informações obtidas através de questionários, detectando uma taxa de uso de cocaína no último mês em $45 \%$ das amostras de fios de cabelo, $20 \%$ das amostras de urina, contra $11 \%$ de relatos de uso através dos questionários. A subestimação de prevalência de uso de drogas quando não são aplicados testes biológicos, como análise de amostras de urina e fios de cabelo, é maior para drogas mais "pesadas" como cocaína e anfetaminas (MCPHILLIPS M, et al. 1997). Análise de fios de cabelo têm sido muito utilizadas para exames ocupacionais e para fins jurídicos na Europa e EUA, e podem indicar o uso de drogas por de longo período, exceto para o uso de Cannabis, mas não está disponível no Brasil. A análise de urina é bastante mais acessível, porém detecta o uso de Cannabis até após 3 semanas de uso da droga, e de cocaína, anfetamina e opiáceos por apenas 48 horas após o consumo. 
Ainda referente às dificuldades deste tipo de estudo, encontramos as particularidades do diagnóstico de abuso e dependência nestes pacientes. Apesar dos critérios para abuso e dependência a substâncias psicoativas parecerem bem definidos, as tentativas de diagnosticar esses pacientes como dependentes ou apresentando uso indevido de drogas encontram alguns problemas. Há evidências de que mesmo o uso infreqüente e de pequenas doses de drogas, legais ou ilegais, levam o indivíduo com transtornos mentais graves a conseqüências mais sérias do que as vistas na população geral e estão associadas a mais efeitos negativos ligados aos transtornos psicóticos, como facilitando reinternações e recaídas (DRAKE et al. 1989; GUPTA et al. 1996; SWOFFORD et al. 1996). Partindo desta premissa, corre-se o risco de associar qualquer uso de drogas por estes pacientes a um uso nocivo de substâncias, e assim, muitos estudos podem estar superestimando o real envolvimento desta população com drogas.

\subsection{Definição dos transtornos mentais graves}

Transtornos mentais graves podem ser definidos como aqueles que levam o indivíduo a apresentar deterioração grave de funcionamento mental e social. Deteriorações como dificuldades no pensamento, interferências no processo do pensamento, experiências desagradáveis com sons, visão ou toque, convicções estranhas ou incomuns, dificuldades em movimentos e ações, concentração diminuída, perda de energia e direcionamento e habilidade reduzida de resolver problemas levam a inaptidões cognitivas (solução ineficiente para problemas, velocidade do aprendizado reduzida), afetivas (ansiedade severa e medo, sentimentos de incapacidade) e comportamentais (dificuldades com ações construtivas), que levam a impossibilidades práticas, como falta de amigos, desemprego, atividades de lazer limitadas, cuidados pessoais pobres, dificuldades com moradia, sobrecarga dos cuidadores. De forma geral, os transtornos mentais graves incluem a esquizofrenia, os transtornos esquizotípicos e transtornos delirantes, os transtornos afetivos bipolares, e quadros graves e incapacitantes de depressão ou ansiedade. 


\subsection{Definição de dependência a drogas psicoativas e abuso/uso nocivo de substâncias}

A definição de dependência a substâncias psicoativas aqui utilizada é baseada nas definições e diretrizes diagnósticas da Classificação Internacional das Doenças, a CID, em sua Décima revisão. Caracteriza-se por "um conjunto de fenômenos fisiológicos, comportamentais e cognitivos, no qual o uso da substância ou classe de substancias alcança uma prioridade muito maior para um determinado indivíduo que outros comportamentos que antes tinham maior valor. Uma característica descritiva central da síndrome de dependência é o desejo (freqüentemente forte, algumas vezes irresistível) de consumir drogas psicoativas (as quais podem ou não terem sido medicamente prescritas), álcool ou tabaco. Pode haver evidência que o retorno ao uso da substância após um período de abstinência leva a um reaparecimento mais rápido de outros aspectos da síndrome do que o que ocorre com indivíduos não dependentes”. O uso nocivo, ou abuso é definido como “um padrão de uso de substância psicoativa que está causando dano à saúde. O dano pode ser físico (como nos casos de hepatite decorrente de auto-administração de drogas injetáveis) ou mental (p. ex. episódios de transtorno depressivo secundário a um grande consumo de álcool)". O uso nocivo não deve ser diagnosticado se a síndrome de dependência, um transtorno psicótico induzido ou outra forma específica de transtorno relacionado ao uso de substancia está presente.

\subsection{Definição de comorbidade}

Nos últimos 10 anos a comorbidade entre uso de drogas psicoativas e transtornos mentais tem sido amplamente reconhecida. As opiniões sobre as causas da co-ocorrência destas patologias varia bastante entre os diferentes autores e também sobre suas implicações sociais e clínicas. O termo comorbidade foi introduzido por FEINSTEIN em 1970 e se refere à presença de qualquer doença coexistindo adicionalmente, em um paciente, com uma doença particular. A presença desta doença adicional pode alterar o curso clínico, o período quando a doença é 
detectada, prognósticos iniciais, eleição da terapêutica preferencial e os cuidados após o tratamento. A comorbidade pode ser definida então, como a expressão de um sinergismo, ou uma potencialização recíproca, entre dois tipo diferente de transtorno.

\subsection{Justificativa}

No Brasil, até o momento são poucos estudos que investigaram essa questão. No entanto, há indicações de que a comorbidade entre transtornos mentais graves e abuso ou dependência de álcool ou drogas seja um problema relevante. Em um estudo sobre a evolução de pacientes com esquizofrenia ou psicoses afins em São Paulo, $12 \%$ dos sujeitos potencialmente elegíveis foram excluídos porque apresentavam claras manifestações clínicas de dependência ao álcool ou Cannabis (MENEZES, 1995). Essa proporção pode ser considerada alta, se comparada com a prevalência de 7,6\% para abuso ou dependência de álcool na população adulta de São Paulo (ALMEIDA- FILHO et al. 1992).

A investigação da ocorrência da comorbidade em questão em um grande centro urbano como São Paulo tem importantes implicações para o planejamento de serviços de saúde mental no país, particularmente em face às mudanças na política de saúde mental que vem ocorrendo nos últimos anos, com priorização do cuidado aos pacientes com transtornos mentais graves baseado em serviços de saúde mental na comunidade. Os resultados de tal estudo também podem possibilitar uma formação mais adequada de profissionais de saúde mental, de forma que eles tenham melhor consciência da dimensão desta questão e possam reconhecer aqueles pacientes que apresentam essa comorbidade, e dar-lhes melhores cuidados profissionais. 


\section{OBJETIVOS}

1. Estimar a prevalência de problemas com uso de álcool e drogas ilícitas, ou se lícitas além da prescrição médica, entre pacientes com psicoses funcionais em 3 regiões da cidade de São Paulo;

2. Investigar quais os fatores associados à ocorrência dessa comorbidade. 


\section{MÉTODO}

\subsection{Desenho:}

Foi realizado um estudo de corte transversal (HENNEKENS, 1987).

\subsection{Amostra:}

Foram definidas 3 regiões geográficas para a realização do estudo. A escolha das regiões foi baseada na organização dos serviços psiquiátricos públicos em cada área, de forma que viabilizassem a execução do estudo. Cada uma das regiões escolhidas possui serviços psiquiátricos, com pelo menos 3 níveis de atenção (hospitais, emergência, ambulatório ou centro de atenção psicossocial), e diferem na forma com que os serviços estão organizados.

- Distrito Administrativo de Pinheiros (Núcleo Regional de Saúde da Capital 1). Essa região, com cerca de 72 mil habitantes, engloba o complexo Hospital das Clínicas, com seu Instituto de Psiquiatria, num hospital-escola de nível terciário. Atende, em suas enfermarias, ambulatório e centro de atenção psicossocial, parte dos moradores da região que sofrem de transtornos mentais graves.

- Distritos Administrativos da Bela Vista, Consolação e Santa Cecília (Núcleo Administrativo de Saúde da Capital 1). Com uma população de aproximadamente 200 mil habitantes, essa área fica na região central da cidade de São Paulo, é coberta pelo serviço de Psiquiatria da Santa Casa de São Paulo, com serviço de emergência psiquiátrica, além de outros serviços ambulatoriais públicos.

- Distritos Administrativos da Casa Verde, Mandaqui e Santana (Núcleo Regional de Saúde da Capital 4). Essa área possui uma população de cerca 
de 337 mil habitantes, na zona norte da cidade de São Paulo. Os serviços psiquiátricos da região incluem uma enfermaria em hospital geral, ambulatórios de saúde mental, o serviço de emergências psiquiátricas do Hospital do Mandaquí, e cerca de 1,000 leitos psiquiátricos conveniados com o SUS, cuja ocupação é organizada pela central de vagas do Município de São Paulo.

Para serem elegíveis, os pacientes deviam residir em uma das áreas acima, ter tido contato com os serviços psiquiátricos do setor público (internação, emergência, serviços intermediários ou atendimento ambulatorial) que cobrem as 3 regiões geográficas, no período de 01/09/97 a 30/11/97, ter idade entre 18 e 65 anos, e diagnóstico clínico de transtorno mental grave (códigos F20-29, F30-31, F32.2 e F33.3, do CID-10). A identificação dos casos por contato com serviços de saúde é indicada pela baixa prevalência de psicoses na comunidade, e pela alta probabilidade de que pessoas acometidas por psicoses venham a buscar ajuda nos serviços de saúde, fazendo com essa seja a forma mais eficiente de se obter uma amostra como a que se pretende.

O cálculo do tamanho da amostra para o estudo de corte transversal foi baseado em uma prevalência esperada de 20\%, com um Intervalo de Confiança de $95 \%$ entre $15 \%$ e $25 \%$. Com esses parâmetros, e estimando-se uma nãoparticipação de $20 \%$, o número de pacientes a serem incluídos no estudo foi de 307 .

\subsection{Instrumentos}

Concomitante à identificação dos pacientes elegíveis, foram definidos os instrumentos utilizados para obtenção dos dados necessários para a estimativa da prevalência do uso de drogas em pacientes com transtornos mentais graves e suas caraterísticas.

Para a determinação dos questionários a serem utilizados na pesquisa fez-se revisão bibliográfica, afim de identificar as melhoras escalas semiestruturadas ou estruturadas. Algumas escalas necessitavam ainda de tradução e/ou revisão para a língua portuguesa e adequação a nossa cultura, quanto aos termos 
aplicados, tipos de benefício securitários, tipos de moradia, tipos de atendimento profissional em saúde mental, tipos de drogas ilícitas disponíveis através do tráfico, tipos e nomes genéricos de medicações psiquiátricas, tipos e nomes genéricos de medicações não psiquiátricas que podem levar a dependência ou abuso de substância e critérios de ajustamento social.

Foi traduzida a escala :

- "Life Chart Rating Form"

Foram revisadas as seguintes escalas que também serão discutidas a posteriori:

- "Schedules for Clinical Assessment in Neuropsychiatriy SCAN": seções 11 e 12

- “ICD-10 CHECKLIST”: versão 1.1-1997, brasileira

Foi elaborado questionário com informações sócio-demográficas e as respectivas folhas de resposta a cada entrevista.

\section{Descrição dos instrumentos}

a) Informações sócio-demográficas: foram obtidas informações sobre idade, sexo, estado civil, procedência e escolaridade, em ficha padronizada para esse objetivo (Apêndice 1).

b) História psiquiátrica: foi utilizada uma ficha padronizada, adaptada da "Life Chart Rating Form", um questionário desenvolvido pela Organização Mundial da Saúde para se obter informações longitudinais para o estudo multicêntrico sobre curso e evolução da esquizofrenia. Neste estudo, apenas a informação sobre o número de internações psiquiátricas anteriores foi utilizado.

c) Diagnóstico psiquiátrico: o critério utilizado foram os do Código Internacional de Doenças, CID-10. O diagnóstico foi obtido a partir das informações constantes nos prontuários médicos, complementadas pela entrevista psiquiátrica, utilizando-se a versão em português do ICD-10 CHECKLIST. 
d) Sintomas psiquiátricos: "Positive and Negative Symptom Schedule (PANSS)". A PANSS é uma escala padronizada para avaliação da presença e intensidade de sintomas psiquiátricos, desenvolvida a partir do BPRS. É dividida em 3 seções: uma seção para sintomas positivos e outra para sintomas negativos da esquizofrenia, e uma seção de sintomas gerais. A escala já está traduzida para o Português, e mostrou boa confiabilidade entre entrevistadores (VESSONI, 1993) (Apêndice 2).

e) Ajustamento social: "Disability Assessment Schedule (DAS)". A DAS foi elaborada para avaliar de forma padronizada e reprodutível o funcionamento social de pacientes com um transtorno psiquiátrico, em diferentes culturas. A DAS, em sua mais recente versão, consiste de 5 seções: comportamento global, papéis sociais, pacientes hospitalizados, fatores modificadores e avaliação global. A primeira seção contém 4 ítens sobre comportamento global e a segunda tem 10 ítens sobre papéis sociais específicos. A seção 3 consiste de 4 sub-seções sobre o funcionamento de pacientes em enfermarias psiquiátricas por mais de 2 semanas. A quarta seção refere-se à avaliação da presença ou ausência de fatores do meio social e familiar do paciente que possam modificar seu ajustamento social. A última seção é uma avaliação global baseada em todas as informações obtidas nas seções anteriores. No presente estudo foram avaliadas as seções 1, 2 e 5. A confiabilidade da versão em português foi avaliada em 20 pacientes com esquizofrenia, e foi bastante satisfatória, sendo que os coeficientes de correlação intra-classe para cada item das seções 1 e 2 variaram de 0,88 a 1,00 (MENEZES; SCAZUFCA, 1993) (Apêndice 3).

f) Uso de álcool e drogas ilícitas: "Schedules of Clinical Assessment in Neuropsychiatry" (SCAN): é uma entrevista semi-estruturada, desenvolvida pela Organização Mundial de Saúde. Em suas seções 11 e 12 são avaliados detalhadamente o uso de álcool, de substâncias psicoativas, com e sem prescrição médica, lícitas e ilícitas, e suas conseqüências físicas, psíquicas e sociais, permitindo um diagnóstico deste uso, a partir dos critérios do CID-10 (Apêndice 4). 


\subsection{Procedimentos}

\subsubsection{Identificação dos Serviços}

Nos distritos definidos para o estudo foram identificados os principais serviços de saúde mental que prestam atendimento a pacientes psicóticos:

- Ambulatório de Saúde Mental do Mandaqui ;

- Pronto Socorro do Mandaqui;

- Hospital das Clínicas (ambulatórios de psiquiatria, enfermaria psiquiátrica e hospital-dia );

- Santa Casa de Misericórdia de São Paulo (Pronto Socorro de Psiquiatria e Ambulatório)

- Hospital do Servidor Público Municipal (Ambulatório)

- Hospital do Servidor Público Estadual (Ambulatório)

- PAS Tucuruvi (Ambulatório)

- PAS Joaquim Eirado (Ambulatório)

- PAS Santa Cecília (Ambulatório)

- PAS Itaim bibi (Hospital dia)

- PAS Humaitá (Ambulatório)

- Ambulatório de Saúde Mental Centro

- Ambulatório de Saúde Mental da Lapa

- Central de Vagas para internação psiquiátrica no município de São Paulo, da Secretaria de Saúde do Estado de São Paulo

- CAPS Itapeva

- NGA Bom Retiro

- NGA Centro 
Uma vez definidos os serviços de saúde mental a serem contatados, foram identificados os responsáveis pelos mesmos e feito contato, inicialmente por telefone para explicação da natureza do estudo em questão. Posteriormente era enviada cópia do resumo do projeto e carta informando o tipo de atividade realizada.

Obtida autorização, era elaborada uma planilha onde constavam os melhores horários possíveis para consulta aos prontuários médicos, dentro da rotina de funcionamento do serviço.

Fez-se então, novo contato com os responsáveis, informando datas, horários e nomes dos auxiliares de pesquisa que fariam a consulta aos prontuários médicos.

\subsubsection{Identificação dos sujeitos elegíveis}

Iniciou-se a consulta a todos os prontuários de pacientes que tiveram contato com os serviços de saúde no período definido (01/09/97 a 30/11/97), para identificar todos os pacientes com hipótese diagnóstica de psicose funcional, definida pelo CID-10 como: transtornos do espectro esquizofrênico e esquizofrenia (F-20, F21,F-22,F-23,F-25), transtornos afetivos (F-30, F31), e transtornos depressivos com sintomas psicóticos (episódio ou recorrentes, F32.3, F33.3), com 18 a 65 anos e endereço em um dos distritos definidos para o estudo.

Desta forma, procurou-se identificar todos os casos potencialmente elegíveis para o estudo. Uma vez que esse número superou o número de entrevistas determinado pelo cálculo do tamanho da amostra, fez-se o planilhamento dos casos elegíveis, em computador, em programa EXCEL, com os seguintes dados: nome, data de nascimento, data do último contato com o serviço dentro do período estudado, hipótese diagnóstica psiquiátrica, endereço completo, número de registro no serviço de origem e nome deste serviço. Essa planilha foi passada ao programa STATA 6.0 (STATACORP, 1999). A partir da lista assim obtida, foram sorteados os sujeitos necessários de acordo com o cálculo do tamanha da amostra, estratificandose por distrito administrativo. 
Esta fase do estudo tinha previsão de três meses de duração, no entanto houveram vários problemas para identificação dos pacientes elegíveis, estendendo-a para dez meses. A seguir são listados os principais problemas com a coleta de dados para recrutamento dos pacientes:

- Acesso aos serviços:

$\checkmark$ Dificuldade de identificar o responsável pelo serviço ou quem poderia ser responsabilizado pela autorização para acesso aos registros de atendimento;

$\checkmark$ Necessidade de aprovação por diversos comitês de ética;

$\checkmark$ Demora por parte dos serviços em responder às solicitações, em aprovar nossa entrada ou em nos receber pessoalmente para apresentação do projeto;

- Acesso aos prontuários:

$\checkmark$ Horários bastante limitados para a consulta aos prontuários;

$\checkmark$ Trabalho manual, exaustivo, em praticamente todos os serviços;

$\checkmark$ Diferentes modos de organização dos serviços entre si;

- Qualidade/Quantidade dos dados dos prontuários:

$\checkmark$ Falta de endereço, muitas vezes não havia qualquer dado;

$\checkmark$ Falta de idade ou data de nascimento;

$\checkmark$ Falta de Hipótese Diagnóstica;

$\checkmark$ Falta de conduta médica, tanto para medicação, como para indicação de internação, alta ou motivo do abandono do tratamento;

$\checkmark$ Letra dos médicos e outros técnicos responsáveis pelo atendimento do paciente;

$\checkmark$ Diferença de definições/conceitos: CID9/CID10;

$\checkmark$ Falta de dados de história e psicopatologia. 


\subsubsection{Treinamento e Estudo Piloto}

Foram contatados sete auxiliares de pesquisa, com experiência em atendimento a pacientes com transtornos mentais, sendo 2 psiquiatras, 1 assistente social, 2 terapeutas ocupacionais e 2 psicólogas que passaram a ser treinados. A eles foi explicado o projeto, meios e finalidade. Foram confeccionados cadernos contendo os questionários, na integra, para uso dos entrevistadores. O treinamento consistiu de:

a) Leitura e discussão de cada escala:

b) Observação de entrevistas: as escalas foram aplicadas em pacientes e familiares disponíveis, que se voluntariaram a participar do treinamento, sem a comorbidade a ser estudada, mas com patologia psiquiátrica grave, pelos pesquisadores responsáveis e segui-se a discussão de cada entrevista.

c) Ainda como observadores, as escalas foram aplicadas a pacientes dependentes de álcool ou drogas ilícitas pelos pesquisadores responsáveis, e discutidas. As escalas foram então aplicadas em pacientes disponíveis, com a referida comorbidade, também pelos pesquisadores responsáveis e então discutidas. Nesta fase foram avaliados 6 pacientes.

d) Realização de entrevistas: as escalas foram aplicadas pelos auxiliares de pesquisa, em pacientes disponíveis, sob supervisão dos pesquisadores responsáveis, segundo mesmo grau de complexidade acima descrito, e seguidas das devidas discussões. Nesta fase foi entrevistado, pelo menos, um paciente por entrevistador.

Foram realizadas 3 entrevistas completas com pacientes e familiares, que permitiram estimar o tempo médio para completar uma avaliação com todos os instrumentos (3 horas), e identificar pequenas adaptações que se mostraram necessárias. 


\subsubsection{Entrevistas com pacientes e informantes}

Passou-se a enviar cartas contendo informações básicas sobre o estudo, um telefone de contato com os coordenadores da pesquisa para tirar dúvidas, remarcar as entrevistas ou demonstrar sua recusa, e uma data provável para a visita pelos auxiliares de pesquisa, aos indivíduos sorteados para serem entrevistados (Apêndice 5). Cada carta foi enviada, via correio, com no máximo 21 e no mínimo 15 dias de antecedência da data provável para a entrevista, com a marcação também de um período (manhã ou tarde) provável para o comparecimento dos entrevistadores a residência dos indivíduos sorteados. A marcação das entrevistas obedeceu a ordem de bairros escolhida a princípio pela proximidade com o Departamento de Medicina Preventiva da FMUSP, para facilitar o contato dos entrevistadores com os coordenadores da pesquisa, em caso de dúvida ou necessidade de orientação. A ordem dos distritos foi realizada como se segue:

- Bela Vista, Santa Cecília e Consolação;

- Pinheiros;

- Santana, Casa Verde e Mandaqui.

Os instrumentos foram divididos em dois blocos, um para a entrevista com o paciente e outro para a entrevista com o familiar ou cuidador responsável:

- Paciente

- Dados sócio demográficos

- Número de internações anteriores

- PANSS

- SCAN

- CHECK-LIST CID-10

- Familiar/cuidador

- DAS 
Em reuniões semanais com os entrevistadores, foram passadas planilhas com os nomes do indivíduos sorteados, seus endereços, data e horário enviados através das cartas para a realização da entrevista, e um mapa da região com a marcação das ruas onde os indivíduos sorteados moram. Foram marcadas 3 entrevistas por período de 5 horas para cada dupla de entrevistadores procurando respeitar proximidade entre os endereços, vias de acesso e tempo de deslocamento entre eles. Optou-se por fazer as entrevistas em dupla, para diminuir o tempo de contato com o indivíduo entrevistado e com sua família, uma vez que, separadamnte, as entrevistas demoram cerca de uma hora e trinta minutos para serem realizadas, e para evitar possíveis problemas de acesso as locais perigosos pelos entrevistadores. Havendo relato por parte do familiar de que o paciente se encontrava internado, fezse contato com o referido hospital, pedindo autorização para realização de entrevista dentro do nosocômio, durante a internação do paciente, com previa autorização do familiar. Nestes casos a DAS era respondida pelo informante em sua residência, ou a seção 3 do mesmo instrumento, aplicada a uma funcionário da enfermagem que tenha contato direto com o paciente durante sua internação, dependendo do tempo de internação.

Muitos indivíduos não puderam ser localizados inicialmente nos endereços constantes na pesquisa aos serviços de saúde mental; retornou-se a oito destes serviços, em busca de novos dados e referências sobre estes pacientes. Em maio de 1999 foi feita consulta ao banco de dados do PROAIM, responsável pelas notificações de óbito da cidade de São Paulo e constatada a morte de 8 indivíduos sorteados.

\subsubsection{Análise}

Criou-se um banco de dados utilizando o programa EPI INFO 6.04. (DEAN et al. 1994) Os dados foram digitados duas vezes para identificar possíveis erros de digitação. 
Este banco de dados foi convertido para o programa STATA 6.0 (STATACORP, 1999), e neste checada a consistência dos dados. As correções necessárias foram feitas voltando-se ao banco original do arquivo em Epi Info (DEAN et al. 1994).

A análise descritiva foi feita utilizando-se o programa STATA 6.0 (STATACORP, 1999).

Esta foi seguida por análise univariada, com estimativas de razões de prevalência e com respectivos intervalos de confiança de 95\%. Para avaliar presença de associações estatísticas, foi utilizado o teste $\chi 2$. Quando eram variáveis categóricas ordenadas, utilizou-se o teste $\chi^{2}$ de tendência linear (KIRKWOOD, 1988). 


\section{RESULTADOS}

A partir dos dados obtidos com o rastreamento de indivíduos potencialmente elegíveis nos serviços de saúde, foram identificados 620 sujeitos que preenchiam os critérios de idade, distrito de moradia, hipótese diagnóstica e data de atendimento no serviço de saúde mental. Destes, foram sorteados 404 indivíduos para a realização das entrevistas.

No período de outubro de 1998 a julho de 1999 foram enviadas cartas a todos os sorteados e realizadas 206 entrevistas. Cento e noventa e oito entrevistas não puderam ser realizadas pelos motivos listados abaixo (TABELA1). Seis pessoas foram referidas por familiares como "desaparecidas" de casa ou terem ido morar na rua $(1,4 \%)$. Oito haviam morrido no último ano $(2,0 \%)$. Em 19 casos $(4,7 \%)$ não foi possível realizar a entrevista por falta de tempo dos indivíduos que estavam trabalhando ou viajando. Houveram 40 recusas, sendo 27 pelo próprio paciente $(6,7 \%)$, duas destas por motivo de doença pessoal grave e 13 recusas dos familiares $(3,2 \%)$, que não concordaram que o paciente mantivesse contato conosco. Em 6 casos os indivíduos foram sorteados erroneamente: três destes foram sorteados 2 vezes por constarem nomes diferentes em diferentes serviços de saúde mental utilizados; um tinha mais de 65 anos quando da data do início do estudo, e as demais, não moravam nos bairros previstos. Por referência de familiares, três indivíduos estão presos; em consulta Vara das Execuções Criminais do Estado de São Paulo foi constatado que um havia fugido do Manicômio Judiciário de Franco da Rocha e estava foragido, um estava preso na Complexo Penitenciário do Carandirú, onde não foi possível contato para a visita e a realização da entrevista, e um estava preso em um Complexo Penitenciário em Presidente Prudente.

Quatorze sujeitos foram excluídos da análise por não preencherem os critérios diagnósticos para os transtornos mentais graves estudados. 
TABELA 1 - ENTREVISTAS REALIZADAS E RAZÕES PARA NÃO REALIZAÇÃO DE ENTREVISTAS $\quad(\mathrm{N}=404)$

\begin{tabular}{lcc}
\hline & $\mathrm{N}$ & $\%$ \\
\hline Entrevistas feitas & 206 & 51,0 \\
Recusas de pacientes & 27 & 6,7 \\
Recusas do familiar & 13 & 3,2 \\
Mudança de cidade/estado/país & 33 & 8,2 \\
Mudança para endereço desconhecido & 38 & 9,4 \\
Morte & 8 & 2,0 \\
Preso & 3 & 0,7 \\
Desaparecido/morando na rua & 6 & 1,4 \\
Endereço não existe/desconhecido no endereço & 45 & 11,1 \\
Erro no sorteio & 6 & 1,4 \\
Não foi possível remarcar a entrevista & 19 & 4,7 \\
Pacientes excluídos da análise & 14 & 3,4 \\
\hline
\end{tabular}

Das 192 entrevistas analisadas, 102 (52,9\%) eram de indivíduos do sexo masculino (TABELA 2); 117 (60,6\%) tinham entre 18 e 44 anos de idade; $101(52,8 \%)$ eram procedentes de outros municípios. Cento e vinte e seis $(65,6 \%)$ tinham até oito anos de estudo. 
TABELA 2 - CARACTERÍSTICAS SÓCIO-DEMOGRÁFICAS DA $\operatorname{AMOSTRA}(N=192)$

\begin{tabular}{lcc}
\hline SEXO & $\mathbf{N}^{\mathbf{0}}$ & $\mathbf{\%}$ \\
\hline Masculino & 102 & 52,9 \\
\hline IDADE & & \\
\hline $18-24$ & 14 & 7,9 \\
$25-34$ & 40 & 20,8 \\
$35-44$ & 63 & 32,8 \\
$45-54$ & 42 & 21,8 \\
54-65 & 33 & 17,1 \\
\hline ESCOLARIDADE & & \\
\hline $0-3$ & 30 & 15,6 \\
$4-8$ & 96 & 50 \\
9 -11 & 34 & 17,7 \\
12 ou mais & 32 & 16,7 \\
\hline PROCEDÊNCIA & & \\
\hline Natural de São Paulo & 91 & 47,2 \\
\hline ESTADO CIVIL & & \\
\hline Solteiro & 110 & 57,2 \\
Casado/Amasiado & 44 & 22,1 \\
Separado/Divorciado & 32 & 16,6 \\
Viúvo & 6 & 3,1 \\
\hline
\end{tabular}

O diagnóstico mais prevalente foi o de Esquizofrenia (TABELA3), seguido de Episódio Maníaco ou Transtorno Afetivo Bipolar e Transtornos Depressivos com Sintomas Psicóticos. Quarenta indivíduos (20,8\%) nunca haviam sido internados em hospitais psiquiátricos para tratamento de transtorno mental e 49 $(25,2 \%)$ tiveram mais de dez internações anteriores. Sessenta e oito sujeitos $(36,1 \%)$ foram considerados como tendo um bom ajustamento social, e $96(51,1 \%)$, um ajustamento social regular; apenas 24 (12,8\%), foram considerados como tendo um ajustamento social pobre. Quanto à sintomatologia psiquiátrica apresentada nas duas semanas anteriores à entrevista, a média da pontuação obtida nos sintomas positivos foi de 11,5, com um desvio padrão de 5,6 pontos; a média dos sintomas negativos foi 
de 14,8, desvio padrão de 8,6; os sintomas psiquiátricos gerais obtiveram maiores pontuações, 25,9 pontos na média, com desvio padrão de 8,5; a média da pontuação total dos sintomas psiquiátricos foi de 52,0 pontos, com desvio padrão de 19,1 .

TABELA 3 - CARACTERÍSTICAS PSIQUIÁTRICAS DA AMOSTRA (N=192)

\begin{tabular}{|c|c|c|}
\hline DIAGNÓSTICO & $\mathbf{N}$ & $\%$ \\
\hline Esquizofrenia & 113 & 58,8 \\
\hline Transtornos do espectro da esquizofrenia & 12 & 6,3 \\
\hline Transtorno afetivo bipolar & 46 & 24 \\
\hline Depressão grave com sintomas psicóticos & 15 & 7,8 \\
\hline Transtorno esquizoafetivo & 6 & 3,1 \\
\hline \multicolumn{3}{|l|}{ INTERNAÇÕES ANTERIORES } \\
\hline Nenhuma & 40 & 20,8 \\
\hline $1-3$ & 60 & 31,2 \\
\hline $4-9$ & 43 & 22,4 \\
\hline 10 ou mais & 49 & 25,5 \\
\hline \multicolumn{3}{|l|}{ AJUSTAMENTO SOCIAL* } \\
\hline Bom & 68 & 36,1 \\
\hline Regular & 96 & 51,1 \\
\hline Pobre & 24 & 12,8 \\
\hline PANSS & Média & D.P. $P^{(1)}$. \\
\hline Sintomas Positivos** & 11,5 & 5,6 \\
\hline Sintomas Negativos $* * *$ & 14,8 & 8,6 \\
\hline Sintomas Gerais*** & 25,9 & 8,5 \\
\hline Total $* * *$ & 52,0 & 19,1 \\
\hline
\end{tabular}

Cento e setenta e cinco $(91,1 \%)$ indivíduos referiram ter usado bebidas alcoólicos durante a vida (TABELA 4) sendo que vinte e nove $(15,1 \%)$ fizeram uso apenas uma ou duas vezes na vida; dos outros $146(76 \%)$ indivíduos que fizeram uso de álcool mais que duas vezes na vida, $82(56,1 \%)$ beberam nos últimos 
12 meses, sendo que 45 (30,4\%) ingeriram bebidas alcoólicas menos que uma vez por mês e $2(1,4 \%)$ relataram ter bebido diariamente neste ano. Quanto à quantidade ingerida habitualmente de álcool, 58 (70,7\%) indivíduos referiram consumir entre $1 \mathrm{e}$ 2 doses-padrão de bebidas alcoólicas. Quarenta e seis (56,5\%) sujeitos negaram usar, mesmo que eventualmente, maiores quantidades de álcool. Não foi possível precisar a freqüência de episódios de uso mais pesado de álcool para 15 (18,5\%) indivíduos. Nove indivíduos $(11,1 \%)$ haviam consumido bebidas alcoólicas nas últimas 24 horas antes da entrevista e $20(24,6 \%)$ entre o último mês e seis meses passados; vinte $(24,6 \%)$ consumiram álcool entre os últimos 6 meses e 1 ano da data da entrevista. Um $(1,2 \%)$ indivíduo não conseguiu precisar seu último uso.

Quatorze (7,3\%) indivíduos entrevistados preencheram pelo menos um dos critérios diagnósticos para abuso de álcool pelo CID-10 e 6 (3,12\%) apresentaram três ou mais critérios, recebendo o diagnóstico de Dependência ao Álcool. 
TABELA 4 -: PADRÕES DE CONSUMO DE ÁLCOOL (N=192)

\begin{tabular}{|c|c|c|}
\hline Consumo médio diário & $\mathrm{n}=\mathbf{8 2}$ & $\%$ \\
\hline 1-2 doses-padrão & 58 & 70,7 \\
\hline 3-4 doses-padrão & 15 & 18,3 \\
\hline 5-9 doses-padrão & 6 & 7,3 \\
\hline 10-14 doses-padrão & 1 & 1,2 \\
\hline 15-19 doses-padrão & 1 & 1,2 \\
\hline Maior uso diário de álcool & $n=82$ & $\%$ \\
\hline Sem episódios pesados & 46 & 56,1 \\
\hline 1-2 doses-padrão & 6 & 7,3 \\
\hline 3-4 doses-padrão & 8 & 9,7 \\
\hline 5-9 doses-padrão & 11 & 13,4 \\
\hline 10-14 doses-padrão & 3 & 3,6 \\
\hline 15-19 doses-padrão & 1 & 1,2 \\
\hline 20-25 doses-padrão & 4 & 4,8 \\
\hline \multirow[t]{2}{*}{25 ou mais doses-padrão } & 3 & 3,6 \\
\hline & $\mathrm{n}=\mathbf{8 2}$ & $\%$ \\
\hline Sem episódios pesados & 46 & 56,5 \\
\hline Ocasionalmente, menos que 1 vez por mês & 15 & 18,5 \\
\hline Uma vez por mês & 2 & 2,4 \\
\hline Mais que uma vez por mês & 2 & 2,4 \\
\hline Uma ou mais vezes por semana & 1 & 1,2 \\
\hline Não soube precisar & 15 & 18,5 \\
\hline
\end{tabular}




\begin{tabular}{lcc}
...continuação & n=191 & \% \\
\hline Último uso * & 9 & 11,1 \\
\hline Nas últimas 24 horas & 3 & 3,7 \\
1-3 dias atrás & 14 & 17,2 \\
4-7 dias atrás & 14 & 17,2 \\
De 2 semanas a 1 mês atrás & 20 & 24,6 \\
De 1 mês a seis meses atrás & 20 & 24,6 \\
De seis meses a um ano atrás & 1 & 1,2 \\
\hline Não soube precisar & $\mathbf{n = 1 9 2}$ & $\mathbf{\%}$ \\
\hline Dependência de álcool & 9 & 4,6 \\
\hline Um critério positivo & 5 & 3,1 \\
Dois critérios positivo & 6 & 3,12 \\
\hline Três ou mais critérios & $\mathbf{1 4}$ & $\mathbf{7 , 3}$ \\
\hline Abuso de álcool & * uma entrevista não computada por falta de confirmação dos dados &
\end{tabular}

Cento e noventa e um indivíduos $(99,4 \%)$ referiram ter feito uso de alguma substância psicotrópica durante suas vidas, sendo os medicamentos psiquiátricos sob prescrição médica as substâncias mais consumidas; apenas 1 indivíduo negou o uso de medicação psiquiátrica. Dezesseis $(8,3 \%)$ indivíduos referiram o uso de alguma substância ilícita, ou se lícita, sem ou além da prescrição médica (TABELA5). Destes, 10 (5,2\%) referiram uso de Cannabis no último e 5 $(2,6 \%)$ preencheram critérios para Dependência a Cannabis. Cinco $(2,6 \%)$ indivíduos referiram uso de cocaína no último ano e 2 (1\%) preenchem os critérios para Dependência a Cocaína. Nenhum indivíduo relatou uso desta droga por via intravenosa, nem na forma fumada ("crack"). Oito pessoas $(4,1 \%)$ fizeram uso de benzodiazepínicos além da prescrição médica ou mesmo sem prescrição, sendo que 2 (1\%) referiram sintomas de dependência. Quatro indivíduos (2\%) referiram uso de outras drogas (solventes, inalantes ou anticolinérgicos), sendo $1(0,5 \%)$ com sintomas de dependência. Não houve nenhuma referência ao uso de opiáceos e anfetaminas, prescritos ou não; também não houve relato de uso de "ecstasy" e alucinógenos, naturais ou sintéticos, no ano anterior à pesquisa. 
Vinte sujeitos (10,4\%, IC 95\%: 6,5 a 15,6 ) preencheram critérios para abuso de álcool e outras substâncias psicoativas. Quatorze (7,3\%) preencheram critérios para abuso de álcool e 9 (4,7\%) indivíduos possuíam critérios para abuso de drogas psicoativas; 3 indivíduos preencheram critérios para abuso de álcool e de drogas. A prevalência para dependência de qualquer substância foi de 5,7\%, (IC 95\%: 2,4 a 9), sendo que 6 indivíduos (3,12\%) preencheram critérios para dependência de álcool, 6 (3,12\%), para dependência de drogas e 1 indivíduo preencheu ambos os critérios.
TABELA 5 - PADRÃO DE CONSUMO DE SUBSTÂNCIAS PSICOATIVAS ILÍCITAS OU FORA DA PRESCRIÇÃO, NOS ÚLTIMOS 12 $\operatorname{MESES}(\mathrm{N}=192)$

\begin{tabular}{rll}
\hline & N
\end{tabular}

Uso de qualquer substância

Abuso de qualquer substância

Dependência de qualquer substância

\section{CANNABIS}

Uso

\section{Freqüência de uso de Cannabis}

Até 5 vezes no período

6- 12 vezes no período

Aproximadamente mensal

Aproximadamente semanal

Aproximadamente diário, algum tempo no último ano

Aproximadamente diário, repetidas vezes no último ano

Aproximadamente diário, por pelo menos um mês
8,3

$9 \quad 4,7$

$6 \quad 3,12$

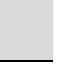




\begin{tabular}{|c|c|c|}
\hline COCAÍNA & $\mathbf{N}$ & $\%$ \\
\hline Uso de cocaína & 5 & 2,6 \\
\hline \multicolumn{3}{|l|}{ Freqüência de uso de cocaína } \\
\hline Até 5 vezes no período & 2 & 1 \\
\hline Aproximadamente mensal & 1 & 0,5 \\
\hline Aproximadamente diário, algum tempo no último ano & 1 & 0,5 \\
\hline Aproximadamente diário, por pelo menos um mês & 1 & 0,5 \\
\hline \multicolumn{3}{|l|}{ Uso mais recente de cocaína } \\
\hline $1-6$ meses & 2 & 1 \\
\hline 6-12 meses & 3 & 1,5 \\
\hline Dependência & 2 & 2,61 \\
\hline \multicolumn{3}{|l|}{ BENZODIAZEPÍNICOS } \\
\hline Uso & 8 & 4,1 \\
\hline \multicolumn{3}{|l|}{ Freqüiência de uso de BZD } \\
\hline Até 5 vezes no período & 3 & 1,5 \\
\hline Aproximadamente diário, algum tempo no último ano & 2 & 1 \\
\hline Aproximadamente diário, repetidas vezes no último ano & 1 & 0,5 \\
\hline Aproximadamente diário, por pelo menos um mês & 2 & 1 \\
\hline \multicolumn{3}{|l|}{ Uso mais recente de $\mathrm{BZD}$} \\
\hline Nas últimas 24 horas & 2 & 1 \\
\hline No último mês & 1 & 0,5 \\
\hline $1-6$ meses & 3 & 1,5 \\
\hline 6-12 meses & 1 & 0,5 \\
\hline Dependência & 2 & 1 \\
\hline \multicolumn{3}{|l|}{ SOLVENTES E INALANTES } \\
\hline Uso & 1 & 0,5 \\
\hline \multicolumn{3}{|l|}{ Freqüência: } \\
\hline Até 5 vezes no período & 1 & 0,5 \\
\hline Último uso: 24 horas & 1 & 0,5 \\
\hline Dependência & $\mathbf{0}$ & $\mathbf{0}$ \\
\hline \multicolumn{3}{|l|}{ OUTRAS DROGAS (ANTICOLINÉRGICOS) } \\
\hline Uso & 3 & 1,5 \\
\hline \multicolumn{3}{|l|}{ Freqüência de uso de anticolinérgicos } \\
\hline Até 5 vezes no período & 2 & 1 \\
\hline Aproximadamente diário, por pelo menos um mês & 1 & 0,5 \\
\hline \multicolumn{3}{|l|}{ Último uso } \\
\hline Nas últimas 24 horas & 1 & 0,5 \\
\hline No último mês & 1 & 0,5 \\
\hline 6-12 meses & 1 & 0,5 \\
\hline Dependência & 1 & 0,5 \\
\hline
\end{tabular}


Os indivíduos do sexo masculino apresentaram um risco, para o abuso de álcool, de 2,21, sendo que 9,8\% deles relataram o abuso, frente a 4,4\% das mulheres. Na amostra analisada, não houve diferença significativa de abuso de álcool associado ao estado civil. Nenhum indivíduo de idade entre 55 e 65 anos referiu sintomas de abuso de álcool, sendo que 7 indivíduos o fizeram na faixa etária de 35 a 44 anos. Não se encontrou diferença significativa estatisticamente quantos aos anos de educação. Nove indivíduos nascidos em São Paulo (9,9\%) apresentaram critérios para abuso de álcool, com um risco relativo de 1,0 quando comparados aos indivíduos migrantes(RR: 0,50).

Os pacientes com diagnóstico de doenças esquizoafetivas tiveram RR: 3,14 e os com quadros do espectro da esquizofrenia, RR: 3,14, quando comparados os com diagnóstico de esquizofrenia. Também não se encontrou diferença estatisticamente significante quando avaliada o número de internações psiquiátricas anteriores e abuso de álcool. Nenhum sujeito recebeu o diagnóstico de abuso de álcool apresentou ajustamento social pobre, enquanto $10,4 \%$ dos indivíduos com ajustamento social regular referiram sintomas.

Diferença significativa estatisticamente foi encontrada nas pontuações entre sintomas negativos avaliados na PANSS; indivíduos que abusam de álcool (média 10,6) apresentaram significativamente menos sintomas negativos que os não abusadores (média 15,1; $p$ 0,005). Sintomas positivos e pontuação total não apresentaram diferenças entre abusadores de álcool e não abusadores (positivo: 13,1 e 11,4 , respectivamente, $p \quad 0,25$; total: 50,$3 ; 52,2$ respectivamente, $p 0,73$ ).

Os indivíduos do sexo masculino apresentaram um RR: 7,06 (TABELA 7) e os casados/amasiados, um RR: 0,5, quando avaliados para abuso de substâncias psicoativas que não o álcool. Dos indivíduos nascidos em São Paulo, 6 (6,6\%) relataram abuso de drogas. Nenhum indivíduo nas faixas etárias entre 18-24 anos e 55-65 anos relataram abuso de substâncias. Três $(23,1 \%$, RR: 9,42) dos pacientes com o diagnóstico de transtornos do espectro esquizofrênico relataram sintomas de abuso de substâncias, enquanto nenhum paciente com diagnóstico de transtorno depressivo ou esquizoafetivo apresentou critérios de abuso. 
Também não se encontrou diferença significativa estatisticamente quando avaliado o número de internações psiquiátricas anteriores. Apenas um indivíduo foi avaliado como tendo um ajustamento social ruim e fazer abuso de drogas; 3 indivíduos com ajustamento social regular (3,1\%) abusam de drogas; 7,3\% dos indivíduos com bom ajustamento social também abusam de substâncias.

Novamente se encontra diferença significativa estatisticamente quando se avaliam sintomas negativos de esquizofrenia destes pacientes, onde a média de pontuação para os pacientes que abusam de drogas foi de $9,8(p 0,006)$ e para os não abusadores de 15,0 pontos. Não se encontra diferença estatisticamente significante nos sintomas positivos (11,5 para não abusadores, 11,4 para abusadores, $p 0,98)$ e em relação a pontuação total $(52,2 ; 48,1$, respectivamente).

TABELA 6 - ASSOCIAÇÕES ENTRE CARACTERÍSTICAS DOS INDIVÍDUOS E ABUSO DE ÁLCOOL $(N=192)$

\begin{tabular}{lccccc}
\hline N(\%) & $\begin{array}{c}\text { ABUSO } \\
\text { ÁLCOOL }\end{array}$ & RR & IC95\% & p \\
\hline SEXO & & & & & $\mathbf{0 , 1 5}$ \\
\hline Masculino & $102(52,9)$ & $10(9,8)$ & 2,2 & $0,72-6,8$ & \\
Feminino & $90(47,1)$ & $4(4,4)$ & 1 & & \\
\hline ESTADO CIVIL & & & & & $\mathbf{0 , 5 2}$ \\
\hline Solteiro & $110(57,2)$ & $8(7,3)$ & 1 & & \\
Casado/amasiado & $44(22,1)$ & $2(4,5)$ & 0,62 & $0,14-2,83$ & \\
Separado/divorciado & $32(16,6)$ & $4(12,5)$ & 1,7 & $0,55-5,34$ & \\
Viúvo & $6(3,1)$ & 0 & 0 & & \\
\hline PROCEDÊNCIA & & & & & $\mathbf{0 , 1 9}$ \\
\hline Natural de São Paulo & $91(47,2)$ & $9(9,9)$ & 0,5 & $0,17-1,43$ & \\
Migrante & $101(52,8)$ & $5(4,9)$ & 1,0 & & \\
\hline EDUCAÇÃO (anos) & & & & & $\mathbf{0 , 5 4}$ \\
\hline $0-3$ & $30(15,6)$ & $3(10)$ & 1 & & \\
4-8 & $96(50,0)$ & $5(5,2)$ & 0,52 & $0,13-2,05$ & \\
9-11 & $34(17,7)$ & $2(5,9)$ & 0,59 & $0,11-3,29$ & \\
12 ou mais & $32(16,7)$ & $4(12,5)$ & 1,25 & $0,30-5,13$ & \\
\hline
\end{tabular}
continua... 
...continuação

\begin{tabular}{|c|c|c|c|c|c|}
\hline FAIXA ETÁRIA & & & & & $0.41^{(\mathrm{a}}$ \\
\hline $18-24$ & $14(7,9)$ & $1(7,1)$ & 1 & & \\
\hline $25-34$ & $40(20,8)$ & $3(7,5)$ & 1,05 & $0,12-9,23$ & \\
\hline $35-44$ & $63(32,8)$ & $7(11,1)$ & 1,56 & $0,21-11,6$ & \\
\hline $45-54$ & $42(21,8)$ & $3(7,14)$ & 1 & $0,11-8,85$ & \\
\hline $55-65$ & $33(17,1)$ & $0(0)$ & & & \\
\hline DIAGNÓSTICO & & & & & $\mathbf{0 , 5 4}$ \\
\hline Esquizofrenia & $113(58,8)$ & $6(5,3)$ & 1 & & \\
\hline $\begin{array}{l}\text { Transtornos do espectro da } \\
\text { esquizofrenia }\end{array}$ & $12(6,3)$ & $2(16,7)$ & 3,14 & $0,71-13,8$ & \\
\hline Transtorno afetivo bipolar & $46(24)$ & $4(8,7)$ & 1,64 & $0,48-5,54$ & \\
\hline $\begin{array}{l}\text { Depressão grave com } \\
\text { sintomas psicóticos }\end{array}$ & $15(7,8)$ & $1(6,7)$ & 1,26 & $0,16-9,73$ & \\
\hline Transtorno esquizoafetivo & $6(3,1)$ & $1(16,7)$ & 3,14 & $0,45-22,1$ & \\
\hline INTERNAÇÕES & & & & & $0,55^{(\mathrm{a}}$ \\
\hline Nenhuma & $40(20,8)$ & $4(10)$ & 1 & & \\
\hline $1-3$ & $60(31,2)$ & $5(8,3)$ & 0,83 & $0,24-2,92$ & \\
\hline $4-9$ & $43(22,4)$ & $1(2,3)$ & 0,23 & $0,03-1,99$ & \\
\hline 10 ou mais & $49(25,5)$ & $4(8,2)$ & 0,82 & $0,22-3,06$ & \\
\hline AJUSTAMENTO SOCIAL* & & & & & $0,76^{(\mathrm{a}}$ \\
\hline Bom & $68(36,1)$ & $4(5,9)$ & 1 & & \\
\hline Regular & $96(51)$ & $10(10,4)$ & 1,77 & $0,58-5,41$ & \\
\hline Ruim & $24(12,7)$ & $0(0)$ & & & \\
\hline PANSS & Média (DP) & Média (DP) & & & \\
\hline Sintomas Positivos** & $11,4(5,5)$ & $13,1(5,9)$ & & & 0,25 \\
\hline Sintomas Negativos $* * *$ & $15,1(8,8)$ & $10,6(4,8)$ & & & 0,005 \\
\hline Total $* * *$ & $52,2(19,4)$ & $50,4(15,0)$ & & & $\mathbf{0 , 7 3}$ \\
\hline
\end{tabular}

* não foram obtidas informações de 4 indivíduos

** não foram obtidas informações de 3 indivíduos

*** não foram obtidas informações de 5 indivíduos

(a)

chi quadradro para tendência linear 
TABELA 7 - ASSOCIAÇÕES ENTRE CARACTERÍSTICAS DOS INDIVÍDUOS E ABUSO DE SUBSTÂNCIAS PSICOATIVAS (N=192)

\begin{tabular}{|c|c|c|c|c|c|}
\hline & $\mathbf{N}(\%)$ & $\begin{array}{l}\text { ABUSO } \\
\text { DROGAS }\end{array}$ & $\mathbf{R R}$ & IC95\% & $\mathbf{p}$ \\
\hline SEXO & & & & & $\mathbf{0 , 0 3}$ \\
\hline Masculino & $102(52,9)$ & $8(7,8)$ & 7,0 & $0,90-55,3$ & \\
\hline Feminino & $90(47,1)$ & $1(1,11)$ & 1 & & \\
\hline ESTADO CIVIL & & & & & 0,48 \\
\hline Solteiro & $110(57,2)$ & $5(4,5)$ & 1 & & \\
\hline Casado/amasiado & $44(22,1)$ & $1(2,3)$ & 0,5 & $0,06-4,1$ & \\
\hline Separado/divorciado & $32(16,6)$ & $3(9,4)$ & 2,06 & $0,52-8,2$ & \\
\hline Viúvo & $6(3,1)$ & 0 & & & \\
\hline PROCEDÊNCIA & & & & & 0,23 \\
\hline Natural de São Paulo & $91(47,2)$ & $6(6,6)$ & 1 & & \\
\hline Migrante & $101(52,8)$ & $3(3,0)$ & 0,45 & $0,12-1,75$ & \\
\hline EDUCAÇÃO (anos) & & & & & $\mathbf{0 , 5 1} 1^{\text {(a) }}$ \\
\hline $0-3$ & $30(15,6)$ & $1(3,3)$ & 1 & & \\
\hline $4-8$ & $96(50,0)$ & $4(4,2)$ & 1,25 & $0,15-10,7$ & \\
\hline $9-11$ & $34(17,7)$ & $2(5,9)$ & 1,76 & $0,17-18,5$ & \\
\hline 12 ou mais & $32(16,7)$ & $2(6,2)$ & 1,18 & $0,17-19,6$ & \\
\hline FAIXA ETÁRIA & & & & & $\mathbf{0 , 4 0} 0^{(\mathrm{a})}$ \\
\hline $18-24$ & $14(7,9)$ & $0(0)$ & & & \\
\hline $25-34$ & $40(20,8)$ & $3(7,5)$ & & & \\
\hline $35-44$ & $63(32,8)$ & $4(6,3)$ & & & \\
\hline $45-54$ & $42(21,8)$ & $2(4,8)$ & & & \\
\hline $55-65$ & $33(17,1)$ & $0(0)$ & & & \\
\hline DIAGNÓSTICO & & & & & 0,009 \\
\hline Esquizofrenia & $113(58,8)$ & $3(2,7)$ & 1 & & \\
\hline $\begin{array}{l}\text { Transtornos do espectro } \\
\text { da esquizofrenia }\end{array}$ & $12(6,3)$ & $3(23,1)$ & 9,42 & $2,13-41,6$ & \\
\hline Transtorno afetivo bipolar & $46(24)$ & $3(6,5)$ & 2,45 & $0,54-11,7$ & \\
\hline $\begin{array}{l}\text { Depressão grave com } \\
\text { sintomas psicóticos }\end{array}$ & $15(7,8)$ & 0 & & & \\
\hline Transtorno esquizoafetivo & $6(3,1)$ & 0 & & & \\
\hline INTERNAÇÕES & & & & & $0,39^{(a)}$ \\
\hline Nenhuma & $40(20,8)$ & $3(7,5)$ & 1 & & \\
\hline $1-3$ & $60(31,2)$ & $3(5)$ & 0,67 & $0,14-3,14$ & \\
\hline $4-9$ & $43(22,4)$ & $1(2,3)$ & 0,31 & $0,03-2,86$ & \\
\hline 10 ou mais & $49(25,5)$ & $2(4,1)$ & 0,54 & $0,09-3,10$ & \\
\hline
\end{tabular}


...continuação

\begin{tabular}{|c|c|c|c|c|c|}
\hline & $\mathbf{N}(\%)$ & $\begin{array}{l}\text { ABUSO } \\
\text { DROGAS }\end{array}$ & $\mathbf{R R}$ & IC95\% & $\mathbf{p}$ \\
\hline \multicolumn{5}{|c|}{ AJUSTAMENTO SOCIAL* } & $\mathbf{0 , 3 3 ^ { ( \mathbf { a } ) }}$ \\
\hline Bom & $68(36,1)$ & $5(7,3)$ & 1 & & \\
\hline Regular & $96(51)$ & $3(3,1)$ & 0,43 & $0,1-1,72$ & \\
\hline Ruim & $24(12,7)$ & $1(4,7)$ & 0,57 & $0,07-4,61$ & \\
\hline PANSS & Média(DP) & Média(DP) & & & \\
\hline Sintomas Positivos ** & $11,5(5,6)$ & $11,4(5,4)$ & & & 0,98 \\
\hline Sintomas Negativos $* * *$ & $15,0(8,7)$ & $9,8(4,3)$ & & & $\mathbf{0 , 0 0 6}$ \\
\hline Total $* * *$ & $52,2(19,1)$ & $48,1(20,1)$ & & & $\mathbf{0 , 5 3}$ \\
\hline
\end{tabular}




\section{TABELA 8 - ASSOCIAÇÕES ENTRE CARACTERÍSTICAS DOS INDIVÍDUOS E ABUSO DE ÁLCOOL E SUBSTÂNCIAS PSICOATIVAS $(N=192)$}

\begin{tabular}{|c|c|c|c|c|c|}
\hline & $\mathbf{N}(\%)$ & $\begin{array}{l}\text { ABUSO } \\
\text { ÁLCOOL } \\
\text { DROGAS }\end{array}$ & $\mathbf{R R}$ & IC95\% & $\mathbf{p}$ \\
\hline SEXO & & & & & 0,04 \\
\hline Masculino & $102(52,9)$ & $15(14,1)$ & 2,65 & $1,0-6,99$ & \\
\hline Feminino & $90(47,1)$ & $5(5,5)$ & 1 & & \\
\hline ESTADO CIVIL & & & & & $\mathbf{0 , 3 0}$ \\
\hline Solteiro & $110(57,2)$ & $11(10)$ & 1 & & \\
\hline Casado/amasiado & $44(22,1)$ & $3(6,8)$ & 0,68 & $0,2-2,3$ & \\
\hline Separado/divorciado & $32(16,6)$ & $6(18,8)$ & 1,88 & $0,75-4,67$ & \\
\hline Viúvo & $6(3,1)$ & 0 & & & \\
\hline PROCEDÊNCIA & & & & & 0,10 \\
\hline Natural de São Paulo & $91(47,2)$ & $13(14,3)$ & 1 & & \\
\hline Migrante & $101(52,8)$ & $7(6,9)$ & 0,49 & $0,20-1,16$ & \\
\hline EDUCAÇÃO (anos) & & & & & $\mathbf{0 , 3 2} 2^{(\mathrm{a})}$ \\
\hline $0-3$ & $30(15,6)$ & $3(10)$ & 1 & & \\
\hline $4-8$ & $96(50,0)$ & $8(8,3)$ & 0,83 & $0,24-2,94$ & \\
\hline $9-11$ & $34(17,7)$ & $4(11,8)$ & 1,18 & $0,29-4,84$ & \\
\hline 12 ou mais & $32(16,7)$ & $5(15,6)$ & 1,55 & $0,41-5,98$ & \\
\hline FAIXA ETÁRIA & & & & & $0,12^{(a)}$ \\
\hline $18-24$ & $14(7,9)$ & $1(7,1)$ & 1 & & \\
\hline $25-34$ & $40(20,8)$ & $4(10)$ & 1,40 & $0,17-11,5$ & \\
\hline $35-44$ & $63(32,8)$ & $11(17,5)$ & 2,44 & $0,34-17,4$ & \\
\hline $45-54$ & $42(21,8)$ & $4(9,5)$ & 1,33 & $0,16-11,0$ & \\
\hline $55-65$ & $33(17,1)$ & $0(0)$ & & & \\
\hline DIAGNÓSTICO & & & & & $\mathbf{0 , 2 2}$ \\
\hline Esquizofrenia & $113(58,8)$ & $8(7,1)$ & 1 & & \\
\hline $\begin{array}{l}\text { Transtornos do espectro da } \\
\text { esquizofrenia }\end{array}$ & $12(6,3)$ & $3(25)$ & 3,53 & $1,08-11,5$ & \\
\hline Transtorno afetivo bipolar & $46(234)$ & $7(15,2)$ & 2,15 & $0,83-5,58$ & \\
\hline Depressão com sintomas psicóticos & $15(7,8)$ & $1(6,7)$ & 0,94 & $0,13-7,01$ & \\
\hline Transtorno esquizoafetivo & $6(3,1)$ & $1(16,7)$ & 2,35 & $0,35-15,9$ & \\
\hline
\end{tabular}




\begin{tabular}{|c|c|c|c|c|c|}
\hline & $\mathbf{N}(\%)$ & $\begin{array}{l}\text { ABUSO } \\
\text { ÁLCOOL } \\
\text { DROGAS }\end{array}$ & $\mathbf{R R}$ & IC95\% & $\mathbf{p}$ \\
\hline INTERNAÇÕES & & & & & $\mathbf{0 , 3 3}{ }^{(\mathrm{a})}$ \\
\hline Nenhuma & $40(20,8)$ & $6(15)$ & 1 & & \\
\hline $1-3$ & $60(31,2)$ & $7(11,7)$ & 0,78 & $0,28-2,14$ & \\
\hline $4-9$ & $43(22,4)$ & $2(4,7)$ & 0,31 & $0,07-1,45$ & \\
\hline 10 ou mais & $49(25,5)$ & $5(10,2)$ & 0,68 & $0,22-2,07$ & \\
\hline AJUSTAMENTO SOCIAL* & & & & & $0,64^{(a}$ \\
\hline Bom & $68(36,1)$ & $7(10,3)$ & 1 & & \\
\hline Regular & $96(51)$ & $12(12,5)$ & 1,2 & $0,5-2,92$ & \\
\hline Ruim & $24(12,7)$ & $1(4,2)$ & 0,4 & $0,05-3,12$ & \\
\hline PANSS & Média (DP) & Média (DP) & & & \\
\hline Sintomas Positivos** & $11,4(5,5)$ & $12,3(5,7)$ & & & $\mathbf{0 , 5 2}$ \\
\hline Sintomas Negativos $* * *$ & $15,3(8,9)$ & $10,5(4,7)$ & & & $\mathbf{0 , 0 0 1}$ \\
\hline Total $* * *$ & $52,4(19,3)$ & $49,0(17,4)$ & & & $\mathbf{0 , 4 5}$ \\
\hline
\end{tabular}

Quando pacientes que abusam de álcool e de drogas foram avaliados conjuntamente, (TABELA 8) indivíduos dos sexo masculino apresentaram RR: 2,65 (14,1\% abusam de substâncias). Não se encontrou diferença significativa estatisticamente quando avaliados procedência, estado civil, diagnóstico, anos de escolaridade, número de internações ou ajustamento social. Treze $(14,3 \%)$ dos nascidos em São Paulo e 18,8\% dos separados/divorciados, referiram abuso de substâncias no último ano. Oito indivíduos (8,3\%) com escolaridade entre 4 e 8 anos relataram abuso de substâncias e/ou álcool. Três indivíduos dos que receberam o diagnóstico de transtornos do espectro da esquizofrenia $(25,0 \%)$ relataram abuso de álcool e/ou drogas, enquanto $15,2 \%$ dos que têm diagnóstico de transtornos do humor bipolar ou mania relataram o abuso. Sete pacientes $(11,7 \%)$ dos que tiveram entre 1 e 3 internações psiquiátricas referiram sintomas de abuso de álcool e/ou drogas. Para aqueles considerados como tendo um ajustamento social regular, o risco relativo foi de 1,21 e os com ajustamento social considerado ruim, RR: 0,40 se comparados a abusadores com um bom ajustamento social. Novamente se encontrou 
diferença estatisticamente significativa entre os sintomas negativos avaliados na PANSS, onde pacientes abusadores de álcool e/ou substâncias apresentaram média de 10,5 pontos $(<p$ 0,001) e não abusadores, média de 15,3 pontos. Nas pontuações totais não houve diferença significativa, com médias de 52,4 para não abusadores e 49 para abusadores $(p 0,45)$, assim como na pontuação para sintomas positivos, com médias de 11,4 e 12,3, respectivamente $(p 0,52)$. 


\section{DISCUSSÃ̃O}

\subsection{Sumário dos Resultados}

Este é o primeiro estudo para avaliar a prevalência do abuso de álcool e drogas em pacientes com diagnóstico de transtorno mental grave realizado em um grande centro de um país em desenvolvimento. Noventa e um por cento dos 192 pacientes entrevistados referiram ter feito uso de bebidas alcoólicas alguma vez na vida, e 42,7\% ingeriram bebidas alcoólicas no último ano, mas apenas 7,3\% preencheram critérios para o diagnóstico de abuso de álcool nos últimos 12 meses. Nos últimos 12 meses, 8,3\% dos entrevistados referiram uso de drogas ilícitas, ou se lícitas, além da prescrição médica, sendo que somente $4,7 \%$ preencheram critérios para o diagnóstico de abuso neste período. A prevalência da comorbidade, independente da substância utilizada, álcool ou drogas, foi 10,4\% (IC95\%: 6,5 a 15,6). A prevalência do abuso de substâncias psicoativas se mostrou maior entre homens do que entre mulheres (RR: 2,65, IC 95\%: 1,0 a 6,99), bem como entre indivíduos separados/divorciados (RR: 1,88, IC 95\%: 0,75 a 4,67). Comparados a indivíduos com o diagnóstico de esquizofrenia, indivíduos com outros transtornos do espectro de esquizofrenia (códigos F21 a F29 da CID 10) apresentaram maior risco de comorbidade (RR: 3,53, IC95\%: 1,08 a 11,56), assim como indivíduos com transtornos esquizoafetivos (RR: 2,35, IC95\%: 0,35 a 15,9), seguidos dos com diagnóstico de transtornos afetivos (RR: 2,15, IC95\%: 0,83 a 5,58). A presença de sintomas negativos de esquizofrenia foi significativamente menor entre os indivíduos que receberam o diagnóstico de abuso de substâncias psicoativas (média 10,5, d.p. 4,7), em relação aos demais indivíduos (média 15,3, d.p. 8,9). estes resultados serão discutidos após considerações sobre as limitações metodológicas do presente estudo. 


\subsection{Limitações Metodológicas}

\subsubsection{Seleção:}

Nenhum serviço que faz atendimento específico a pacientes dependentes de álcool e drogas foi incluído na lista de serviços onde foi realizado o levantamento de pacientes potencialmente elegíveis para o estudo. Pacientes com quadros psicóticos controlados ou não diagnosticados adequadamente podem ser atendidos nestes serviços, e sua não inclusão pode ter contribuído para uma subestimação da prevalência de comorbidade.

Nas consultas aos prontuários dos diferentes serviços, durante a seleção dos indivíduos elegíveis, não foram selecionados pacientes que receberam diagnóstico de psicoses induzidas por álcool e outras drogas ou que apresentavam sintomas psicóticos, depressivos ou maniformes atribuídos pelo médico como decorrentes do uso de substâncias, e que portanto receberam o diagnóstico de psicose induzida por substâncias. O diagnóstico diferencial entre psicose induzida por substâncias e comorbidade é controverso e muitas vezes, difícil de ser caracterizado, senão pelo contínuo acompanhamento do paciente, mantido em abstinência de substâncias psicoativas. Neste sentido, também é possível que essa limitação na seleção de sujeitos para o estudo tenha contribuído uma subestimação da prevalência encontrada.

Nas consultas aos prontuários dos serviços de emergência psiquiátrica, não foram selecionados pacientes com o diagnóstico de intoxicação por álcool ou outras drogas, mesmo quando apresentavam francos sintomas disfuncionais, sugestivos de quadros psicóticos associados. Nestes casos, o diagnóstico médico tendia a valorizar sintomas de intoxicação que explicavam o transtorno do comportamento. Embora o número de pacientes nestas condições seja pequeno, isso pode ter contribuído para a subestimação da comorbidade.

A falta de informações dos prontuários consultados, sobre dados de identificação, endereço, idade ou data de nascimento e diagnóstico, impediu a 
seleção de diversos indivíduos para o estudo. No entanto, provavelmente esta perda foi aleatória, não interferindo na medida da prevalência da comorbidade.

Dois serviços que poderiam ter oferecido atendimento psiquiátrico à população das áreas estudadas foram excluídos por não permitir acesso às informações dos prontuários, sendo um serviço de emergência da zona oeste da cidade de São Paulo e uma enfermaria de psiquiatria em hospital geral universitário. No entanto, a não inclusão destes serviços não deve ter repercutido na estimativa da prevalência, uma vez que ambas as áreas de abrangência destes serviços são cobertas por outras unidades de saúde mental e a maioria das internações solicitadas pelo serviço de emergência são feitas através da Central de Vagas da Secretaria de Saúde, que foi incluída no estudo.

A amostra do presente estudo é composta por pacientes que foram atendidos em serviços públicos, vinculados ao Sistema Único de Saúde (S.U.S) ou ao Plano de Atendimento à Saúde (PAS). Pacientes atendidos exclusivamente em serviços particulares, não foram entrevistados. É possível que pacientes que recebem atendimento particular tenham características diferentes da amostra estudada, inclusive quanto a seu poder aquisitivo e acesso às drogas e álcool. Pacientes atendidos exclusivamente em convênios médicos também não foram incluídos. No entanto, uma vez que, à época do estudo, poucos convênios possuíam atendimento médico psiquiátrico, incluindo internações psiquiátricas, a não inclusão destes pacientes no estudo não deve ter influenciado a prevalência encontrada, uma vez que estes pacientes são encaminhados a atendimento em serviço público quando precisam de internação psiquiátrica.

Pacientes com a comorbidade pesquisada têm maiores taxas de detenção por cometerem mais atos ilegais (BARTELS et al. 1993). Não foi possível consultar, para este estudo, delegacias de polícia, casas de detenção, presídios ou manicômios judiciários em busca de outros indivíduos que preenchessem os critérios para o estudo, e não foi possível a entrevista com três indivíduos sorteados para o estudo, que sabidamente estavam detidos, o que pode ter subestimado a prevalência da comorbidade. 
Não foram entrevistados indivíduos sem residência fixa e moradores de rua. TESSLER; DENNIS (1989) relatam que aproximadamente $10 \%$ a $20 \%$ dos moradores de rua avaliados em seu estudo sofriam de um transtorno mental grave e de problemas com álcool ou outras drogas. No Brasil, HECKERT et al. (1999), em estudo desenvolvido com 83 moradores de rua da cidade de Juiz de Fora, encontraram uma prevalência de $9,6 \%$ de indivíduos com transtornos esquizofreniformes, $32,5 \%$ com transtornos do humor, $82 \%$ de dependentes de álcool e 31,3\% dependentes de drogas, com uma prevalência de comorbidade entre quaisquer transtornos mentais de $78,3 \%$.

A maior limitação quanto a possíveis viéses de seleção diz respeito à alta proporção de não-resposta. Quarenta e nove por cento dos indivíduos sorteados para a inclusão no estudo, não foram entrevistados; 30,8\% sequer foram localizados, sendo que $11,1 \%$ eram desconhecidos no endereço dado ao serviço ou o endereço era inexistente. É possível que haja uma maior proporção de indivíduos com comorbidade entre os não entrevistados. Porém, para que essa não resposta justificasse a baixa prevalência de comorbidade observada, seria necessário que a proporção de indivíduos com duplo diagnóstico, na amostra de não entrevistados fosse 3 a 4 vezes maior que a observada entre os respondentes, para se chegar a uma prevalência de $20 \%$ do total, o que implicaria em ate $40 \%$ de indivíduos com comorbidade nos não entrevistados.

\subsubsection{Informação:}

Toda a informação sobre o uso de álcool e drogas ilícitas, bem como do uso de medicações prescritas pelo médico foram obtidas diretamente com os próprios pacientes. Não foi utilizado nenhuma outra fonte de dados objetiva como informações dos prontuários, médicos responsáveis ou familiares. Também não foi realizado nenhum teste biológico para a detecção do uso de drogas. Isto pode ter implicado na subestimação do consumo e prevalência de abuso de substâncias. 
Mesmo com o uso de critérios para o diagnóstico de abuso e dependência de álcool e drogas psicoativas, como os estabelecidos na CID 10, muitas vezes não é possível precisar se alguns sintomas se devem uso de substâncias ou se fazem parte das manifestações clínicas dos quadros psicóticos (KRANZLE; ROUNSAVILLE, 1998).

Para a avaliação da presença e intensidade de sintomas psicóticos e para a avaliação do ajustamento social dos entrevistados foram utilizadas escalas semi estruturadas (PANSS e DAS respectivamente), que no entanto, requerem avaliação clínica por parte dos entrevistadores. Possíveis erros sistemáticos entre entrevistadores foram minimizados com o treinamento e a supervisão constante desenvolvida junto aos entrevistadores, ao longo do período do trabalho de campo.

\subsubsection{Chance}

Embora a amostra do presente estudo seja maior que as investigadas em outros estudos, (BARBEE et al. 1989; DRAKE et al. 1989; DRAKE et al. 1991; OSHER et al. 1994; MENEZES et al. 1996), o número absoluto de pacientes com comorbidade foi pequeno. Isso faz com que o poder do estudo para detectar associações estatísticas seja baixo.

\subsubsection{Confusão}

Pela pequena prevalência de pacientes com a referida comorbidade encontrada neste estudo optou-se por não fazer a análise multivariada dos dados (HENNEKENS, 1987).

Algumas associações podem estar sendo confundidas por outras, como a baixa prevalência de abuso de substâncias psicoativas encontrada nos pacientes com diagnóstico de esquizofrenia e a presença de sintomas negativos (SERPER et al. 1995). 


\subsection{Interpretação Dos Resultados}

\section{Prevalência}

Os resultados deste estudo sugerem que na população estudada a prevalência de transtornos decorrentes do uso de álcool e outras drogas em pacientes com transtornos mentais graves é mais baixa do que as prevalências encontradas em outros estudos, desenvolvidos nos EUA e Europa (DRAKE; WALLACH, 1993; DUKE et al. 1994; MENEZES et al. 1996; REGIER et al. 1988; REGIER et al. 1990). Essa discrepância de resultados pode ser devida a diversos fatores, incluindo o consumo de substâncias pela população geral na qual estão os sujeitos investigados, o ambiente social onde esses sujeito vivem e aspectos culturais relacionados ao consumo de substâncias.

Estudos na população geral sugerem que a prevalência do uso de substâncias psicoativas é menor no Brasil do que nos EUA. GALDURÓZ et al. (1997) avaliou 2.730 estudantes de primeiro e segundo graus da rede estadual de São Paulo, que responderam a um questionário fechado de auto preenchimento, e encontrou uma prevalência de 6,4\% para uso de Cannabis na vida, com um uso freqüente (mais de 6 vezes nos últimos 30 dias) em $0,9 \%$ da amostra e uso pesado (20 ou mais vezes nos últimos 30 dias) em 0,6\%. Para cocaína, as prevalências encontradas foram de $1,8 \%$ na vida e $0,3 \%$ para uso freqüente e uso pesado. O uso de solventes apresentou uma prevalência na vida de 10,9\%, um uso freqüente em $0,8 \%$ e uso pesado em $0,5 \%$ da amostra entrevistada. O álcool foi a substância mais utilizada pelos estudantes, com uso na vida referido por $74,1 \%$ da amostra, uso freqüente por $14,7 \%$ e uso pesado por $7,3 \%$ dos entrevistados. ANDRADE et al. (1995) realizaram estudo com 2.304 estudantes de uma faculdade de medicina de São Paulo, com dados colhidos entre 1991 e 1993, para avaliar o consumo de drogas e álcool. O álcool foi a substância mais utilizada nos últimos 12 meses, com uma prevalência de 85,5\%. O tabaco foi a segunda substância mais utilizada pelos 
estudantes $(19,8 \%)$. A Cannabis apareceu em terceiro lugar, utilizada por 15,2\% dos entrevistados, seguida dos solventes $(13,3 \%)$ e tranqüilizantes $(7,5 \%)$.

JOHNSTON et al. (1999) conduziram estudo com cerca de 50.000 estudantes de 420 escolas públicas e privadas de nível secundário, nos EUA. Utilizando metodologia semelhante à do estudo citado anteriormente (GALDURÓZ et al. 1997), encontraram prevalências de uso de álcool na vida que variaram de $52,1 \%$ a $80 \%$, conforme o ano de graduação em curso, resultado semelhante ao do estudo brasileiro. Já em relação ao uso de outras substâncias psicoativas, as prevalências foram muito maiores na amostra americana. $\mathrm{O}$ uso de Cannabis na vida foi relatado por até $49,7 \%$ dos estudantes, enquanto o uso de cocaína na vida foi referido por $9,8 \%$ dos entrevistados. O uso de inalantes variou entre 15,4\% e 19,7\%. O uso de substâncias no último ano apresentou variação conforme a série cursada pelo entrevistado, sendo que o uso de Cannabis nos últimos 12 meses foi referido por $37,8 \%$ dos indivíduos que cursavam o " 12 th -grade".

Estudos com a população geral nos EUA mostram padrões de consumo semelhantes, onde o consumo de álcool parece ser similar ao observado no Brasil, mas o consumo de outras substâncias é maior. WARNER et al. (1995) analisaram dados do "National Comorbidity Survey", colhidos com 8.098 indivíduos, não institucionalizados e com residência fixa. Encontraram uma prevalência de uso de drogas ilegais ou sem prescrição médica de $51 \%$ na vida e 15,4\% nos últimos 12 meses, para todos os indivíduos, sendo 64,7\% na vida e de $17,8 \%$ nos últimos 12 meses, entre indivíduos com 25 a 34 anos de idade e de $42,8 \%$ na vida e 23,8\% nos últimos 12 meses entre indivíduos de 15 a 24 anos.

GRANT (1997) utilizando dados do "National Institute In Alcohol Abuse And Alcoholism's National Longitudinal Alcohol Epidemiologic Survey”, avaliou 42.862 indivíduos residentes no EUA, segundo critérios do DSM IV, encontrando uma prevalência de uso de álcool de $66 \%$ na vida e $44,4 \%$ no último ano.

Dados sobre a prevalência de dependência de substâncias apontam para a mesma direção. ALMEIDA-FILHO et al. (1997), em estudo epidemiológico 
de base populacional em três grandes centros brasileiros, avaliaram a presença de sintomas de dependência ao álcool, constatado-o em 5\% da população de Brasília, em 4\% em São Paulo e em 9\% da população de Porto Alegre, sendo que esse diagnóstico foi observado quase que exclusivamente na população masculina. KESSLER et al. (1994) analisando dados do "National Comorbidity Survey" estimou a prevalência de dependência de álcool, em homens em $20,1 \%$, na vida e $10,7 \%$ nos últimos 12 meses e em mulheres, de $8,2 \%$ na vida e 3,7\% nos últimos 12 meses. A prevalência de dependência de drogas nesta população foi de $9,2 \%$ dos homens, na vida e 3,8\% nos últimos 12 meses e de 5,9\% na mulheres, na vida e 1,9\% no último ano. JENKINS et al. (1997), avaliando dados do "National Morbidity Survey", realizado com uma amostra de 10.108 indivíduos na Grã Bretanha, encontrou uma prevalência de dependência de álcool, em homens, no último ano, de 75 por 1000 habitantes e em mulheres, em 21 por 1000 habitantes. A prevalência de dependência de drogas nesta população foi de 29 por 1000 habitantes entre os homens e de 15 por 1000 habitantes em mulheres.

Uma outra possibilidade é que determinantes sócio ambientais podem explicar essas diferenças de resultados. Em países desenvolvidos, pacientes com transtornos mentais graves recebem apoio e cuidados providos pelo Estado, como auxílio à moradia, lares abrigados, empregos supervisionados, auxílio financeiro, e tratamento integral, incluindo visitas domiciliares e obtenção de medicação, estimulando a independência do paciente. Mudanças nos princípios para a organização dos serviços psiquiátricos comunitários na Grã Bretanha direcionaram os serviços para tentar responder às necessidades individuais dos pacientes, e não as institucionais, acreditando que esse objetivo é melhor atingido substituindo-se sistemas de serviços de grandes instituições por um alcance mais equilibrado e flexível de serviços alternativos. Segundo esse modelo, primeiramente delineia-se a gama de necessidades dos pacientes individualmente e então, formula-se uma série de passos para converter as necessidades cumulativas em elementos a serem providos pelos serviços. Desta forma, as necessidades reais dos pacientes psiquiátricos são abordadas pelos serviços de saúde mental. Educação familiar e comunitária, serviços jurídicos, identificação de casos na comunidade, acompanhamento da saúde física e dentária, apoio financeiro, moradia e acompanhamento de moradores de rua, 
reabilitação, espaços de convivência, hospitais-dia e o tratamento psiquiátrico com acompanhamento ambulatorial, leitos psiquiátricos, serviços de intervenção em crises são oferecidos à comunidade (BHUGRA; LEFF, 1993).

No Brasil, o desamparo social ao paciente doente mental leva-o a uma maior dependência da família, e consequentemente, a um maior controle que esta exerce sobre a liberdade do indivíduo. Isso pode ser observado no fato de que, da amostra sorteada para ser entrevistada no presente estudo, 3,2\% dos indivíduos não participaram por impedimento de suas famílias, que se recusaram a permitir que os pacientes fossem inquiridos quanto ao seu desejo de participar ou não do estudo. A menor autonomia e o menor contato social destes pacientes podem estar funcionando como fatores protetores, evitando que os mesmos tenham acesso a ambientes onde possam consumir álcool ou drogas ilícitas. Reforça essa hipótese o fato de que a amostra entrevistada apresentou uma grande porcentagem de sintomas negativos, como isolamento social e um ajustamento social regular, o que parece proteger esses pacientes do abuso de substâncias (SERPER et al. 1995), enquanto a prevalência de cormorbidade foi maior entre os indivíduos com o diagnóstico de transtornos delirantes, indivíduos que pelas próprias características do diagnóstico tendem a apresentar menor comprometimento social do que indivíduos com diagnóstico, por exemplo, de esquizofrenia.

Fatores culturais, como a crença de que "não se deve beber quando se toma remédios", são amplamente difundidas no Brasil. Esta justificativa muitas vezes foi citada, espontaneamente, pelos indivíduos entrevistados, como sendo o motivo pelo qual não usam bebidas alcoólicas. Esse aspecto não foi abordado com maior profundidade no presente trabalho, mas pode ter contribuído para a baixa prevalência de comorbidade observada.

\subsection{IMPLICAÇÕES}

Os resultados deste estudo sugerem a necessidade de uma maior atenção e melhor treinamento das equipes de saúde mental que lidam com pacientes com transtornos mentais graves. No entanto, não foram encontradas evidências que 
justifiquem a criação de novos serviços específicos ou programas especializados para o atendimento desta população.

O presente estudo aponta para a realização de novas investigações sobre a questão da comorbidade entre transtornos mentais graves e dependência de substâncias no Brasil. Uma possibilidade é a pesquisa com subgrupos específicos, visando uma melhor avaliação do impacto da comorbidade sobre a saúde pública, a utilização de serviços de saúde e implicações econômicas. As prevalências encontradas em estudos internacionais variam de $20 \%$ a $75 \%$ das amostras investigadas, e parte desta variação tem sido atribuída ao tipo de amostra investigada. Pesquisas epidemiológicas de base populacional (REGIER et al. 1988; REGIER et al. 1990; DUKE et al. 1994) apresentam prevalências mais baixas. que as observadas entre pacientes internados em hospitais psiquiátricos (SOYKA et al. 1990), entre pacientes atendidos em serviços de emergência psiquiátrica (BARBEE et al. 1989), em indivíduos com história de violência e história forense (BARTELS et al. 1993; YESAVAGE; ZARCONE, 1993), com pacientes freqüentemente re-hospitalizados e com internações prolongadas (SULLIVAN et al. 1998; MENEZES et al. 1996) e moradores de rua (SOYKA et al. 1992; HECKERT et al. 1999).

Pesquisas sobre fatores ambientais e sócio-culturais característicos da população brasileira serão importantes para determinar a relevância destas variáveis na prevalência do uso de substâncias e suas implicações.

Um estudo com o segmento destes pacientes pode ainda ser útil para melhor avaliar, na nossa população, o impacto da comorbidade sobre a evolução clínica e social destes pacientes, ajudando a esclarecer a associação entre a comorbidade, uma pior evolução (DUKE et al. 1994; MENEZES et al. 1996; OSHER et al. 1994) e os fatores associados a esta, ajudando a identificar grupos de maior risco para o uso de substâncias e o planejamento de ações específicas de saúde, adequadas à nossa realidade. 


\section{REFERÊNCIAS BIBLIOGRÁFICAS}

ALMEIDA-FILHO, N. ; MARI, J. J. ; COUTINHO, E. ; FRANÇA, J. F. ; FERNANDES, J; ANDREOLI, S. B. ; BUSNELLO, E. D. Estudo multicêntrico de morbidade psiquiátrica em áreas urbanas brasileiras (Brasília, São Paulo, Porto Alegre). ABP-APAL, v.14, p. 93-104, 1992.

AMERICAN PSYCHIATRIC ASSOCIATION. Diagnostic and statistic manual of mental disorders (third edition, revised) (DMS-III-R). APA, Washington, 1987.

ANDRADE, A. G. ; BASSIT, A. Z. ; MESQUITA, A. M. ; FUKUSHIMA, J. T.; GONÇALVES, E. L. Prevalência do uso de drogas entre alunos da faculdade de medicina da universidade de são Paulo (1991-1993). ABPAPAL, v. 179(2), p. 41-6, 1995.

BABOR, T. F. ; DE LA FUENTE, J. R. ; SAUNDERS, J. ; GRANT, M. Audit: the alcohol use disorders identification test: guidelines for use in primary health care. WHO, Geneva, 1992.

BARBEE, J. G. ; CLARK, R. E. ; CRAPANZANO, M. S. ; HEINTZ, G. C. ; KEHOE, C. E. Alcohol and substance abuse among schizophrenics patients presenting to an emergency psychiatric service. J Nerv Ment Dis., v. 177, p. 400-07, 1989.

BARTELS, S. J. ; DRAKE, R. E. ; WALLACH, M. A. Long-term course of substance use disorders among patients with severe mental illness. Psychitric Services, v. 46, p. 248-251, 1995.

BARTELS, S. J. ; TEAGUE, G. B. ; DRAKE, R. E. ; CLARK, R. E. ; BUSH, P. W. ; NOORDSY, D. L. Substance abuse in schizophrenia: service utilization and costs. J Nerv Ment Dis., v. 181, p. 227-32, 1993.

BHUGRA, D ; LEFF, J. Principles of social psychiatry. 1 Ed., Oxford, Blackweel Scientific Publications, p. 473-89, 1993.

BOYD, J. H. ; BURK, J. D. ; GRUEMBERG, E. ; HOLZER, C. E. ; GEORGE, L. K. ; KARNO, M. ; STOLTZMAN, R. ; MCEVOY, L. ; NESTADT, G. Exclusion criteria of DSM-III: a study of co-occurence of hierarcht-free symptoms. Arch Gen Psychiatry, v. 41, p. 982-87, 1984.

CLARK, R. E. Family costs associates with severe mantal illness and substance use. Hosp Community Psychiatry, v. 45(8), p. 808-13, 1994. 
CLARK, R. E. ; DRAKE, R. E. Expenditures of time and money by families of people whit several mental illness and substance use disorders. Community Ment Health J., v. 30, p. 145-63, 1994.

CUFFEL, B. J. Prevalence estimates of substance abuse in schizophrenia and their correlates. J Jerv Ment Dis., v. 180, p. 589-92, 1992.

CUFFEL, B. J. ; HEITHOFF, K. A. ; LAWSON, W. Correlates of patterns of substance abuse among patients with schizophrenia. Hosp Community Psychiatry, v. 44(3), p. 247-51, 2000.

CUFFEL, B. J.; SHUMWAY, M. ; CHOUlJiAN, M. A. ; MCDONALD, T. A longitudinal study of substance use and community violence in schizophrenia. J Nerv Ment Dis., v. 182, p. 704-08, 1994.

DAVIDSON, D. G. ; RAISTRICK, D. The validity of short alcohol dependence data (SADD) questionnarie: ashort self-report questionnarie for the assessment of alcohol dependence. Br J Addict., v. 81, p. 217-22, 1986.

DRAKE, R. E. ; MCLAUGHLIN, P. ; PEPPER, B. ; MINKOFF, K. Dual diagnosisof major mental illness and substance disorder: an overview. New Dir Ment Health Serv., v. 50, p. 3-12, 1991.

DRAKE, R. E. ; OSHER, F. C. ; WALLACH, M. A. Alcohol use and abuse in schizophrenia. A prospective community study. J Nerv Ment Dis., v. 177, p. 408-414, 1989.

DRAKE, R. E. ; WALLACH, M. A. Moderate drinking among people with severe mental illness. Hosp Community Psychiatry, v. 44(8), p. 780-1, 1993.

DUKE, P. J. ; PANTELIS, C. ; BARNES, T. R. South westminster schizophrenia survey. Alcohol use and its relationship to symptoms, tardive dyskinesia and illness onset. Br J Psychiatry, v. 164, p. 630-6, 1994.

EL GUEBALY, N. Substance abuse and mental disorders: the dual diagnostic concept. Can J Psychiatry, v. 35, p. 261-7, 1990.

DEAN, A. G. ; DEAN, J. A. ; COLOMBIER, D. ; BRENDEL, K. A. ; SMITH, D. C. ; BURTON, A. H. ; DICKER, R. C. ; SULLIVAN, K. ; FAGAN, R. F. ; ARNER, T. G. Epi Info, version 6: a word processing, database, and statistics program for epidemiology on microcomputers. Center for Disease Control and Prevention, Atlanta, Georgia, USA, 1994

GALANTER, M. ; EGELCO, S.; EDWARDS, H. ; VERGARAY, M. A treatment system for combined psychiatric and addictive illness. Addiction, v. 89(10), p. 1227-35, 1994. 
GALDUROZ, J. C. F. ; NOTO, A. R. ; CARLINI, E. A. IV Levantamento Sobre o Uso de Drogas entre Estudantes de Primeiro e Segundo Graus em 10 Capitais Brasileiras-1997. Centro Brasileiro de Informações Sobre Drogas Psicotrópicas - CEBRID, UNIFESP, 1997.

GRANT, B. F. Prevalence and correlates of alcohol use and DSM IV alcohol dependence in the United States: results of the National Longitudinal Alcohol Epidemiologic Survey. J Stud Alcohol, v. 58(5), p. 464-73, 1997.

GRANT, B. F. ; TOWLE, L. H. Standardizard diagnostic interviews for alcohol research. Alcoholism Clin Exp Res., v. 15, p. 102-5, 1991.

GUPTA, S. ; HENDRICKS, S. ; KENKEL, A. M. ; BHATIA, S. C. ; HAFFKE, E. A. Relapse in schizophrenia:is there a relationship to substance abuse? Schizophrenia Res., v. 20, p. 153-6, 1996.

HECKERT, U.; ANDRADE, L.; ALVES, M. J. ; MARTINS, C. Lifetime prevalence of mental disorders among homeless people in a southeast city in Brazil. Eur.Arch.Psychiatric Clin Neurosci., v. 249(3), p. 150-5, 1999.

HENNEKENS, C. H. ; BURING, J. E. Epidemiology in medicine. 1 Ed., Little, Brown and Company, Boston, Massachusetts, 1987

KRANZLER H.; ROUNSAVILle, B. Dual Diagnosis and Treatment. 1 Ed., Marcek Dekker, Inc USA, cap. 1, 1998.

JENKINS, R. ; LEWIS, G. ; BEBBINGTON, P. ; BRUGHA, T. ; FARRELL, M. ; GILL, B. ; MELTZER, H. The National Psychiatric Morbidity Surveys Of Great Britain-inicial findings from the household survey. Psychological Medicine, v. 27, p. 775-89, 1997.

JERREL, J. M. ; RIDGELY, M. S. Comparative effectiveness of trhee approaches to serving people whit severe mental illness and substance abuse disorders. J Nerv Ment Dis, v. 183, p. 566-76, 1995.

JOHNSON, S. Dual diagnosis of severe mental ilness and substance misuse: a case for specialist services? Br J Psychiatry, v. 171, p. 205-08, 1997.

JOHNSTON, L. D. ; O'MALLEY, P. M. ; BACHMAN, J. G. National Survey results on drug abuse from The Monitoring The Future Study: Drug Trends in 1999. http://www.monitoringthefuture.org/ national institute on drug abuse, 1999.

KAY, S. R. ; OPLER, L. A. ; LINDENMAYER, J. P. Reliability and validity of the positive and negative syndrome scale for schizophrenics. Psychiatry Res., v. 23, p. 99-110, 1988. 
KESSLER, R. C. ; MCGONAGLE, K. A. ; ZHAO, S. ; NELSON, C.B. ; HUGHES, M. ; ESHLEMAN, S. ; WITTCHEN, H. U. ; KENDLER, K. S. Lifetime and 12-month prevalence of DSM-III-R psychiatric disorders in United States: results from the National Comorbidity Survey. Arch Gen Psychiatry, v. 51, p. 8-19, 1994.

KIRKWOOD, B.R. Essentials of Medical Statistics. 1 Ed., Oxford, Blacweel Science Publications, 1988.

LEHMAN, A. F. ; HERRON, J. D. ; SCHWARTZ, R. P. ; MYERS, C. Rehabilitation for adults with severe mental illness and substance use disorders. A clinical trial. J Nerv Ment Dis., v. 181, p. 86-90, 1993.

LEY, A. ; JEFFERY, D. P. ; MCLAREN, S. ; SIEGFRIED, N. Treatment programmes for people with both severe mental illness and substance misuse. The Cochrane Library, 1999.

MAYFIELD, D. ; MCLEOD, G. ; HALL, P. The cage questionnarie: validation of a new alcoholism instrument. Am J Psychiatry, v. 131, p. 1121-3, 1974.

MCLEllan, A. T.; KUSHNER, H.; METZGER, D.; PETERS, F. The fifth edition of the addiction severity index. J Subst Abuse Treat., v. 9, p. 199-213, 1992.

MCPHILliPS, M. A. ; KELLY, F. J. ; BARNES, T. R. ; DUKE, P. J. ; GENE-COS, N. ; CLARK, K. Detecting comorbid substance misuse among people with schizophrenia in the community: a study comparing the results of questionnaries with analysis of hair and urine. Schizophrenia Res., v. 25, p. 141-8, 1997.

MENEZES, P. R. The outcome of schizophrenia and related psychoses after hospitalization: a prospective study in São Paulo, Brazil. Tese (PhD)University of London, 1995.

MENEZES, P. R. ; SCAZUFCA, M. Estudo da confiabilidade de versão em Português da "Escala de Avaliação da Incapacitação Psiquiátrica (WHO/DAS)". ABP-APAL, v. 15, p. 65-7, 1993.

MENEZES, P. R. ; JOHNSON, S. ; THORNICROFT, G. ; MARSHALL, J. ; PROSSER, D. ; BEBBINGTON, P. ; KUIPERS, E. Drug and alcohol problems among individuals with severe mental illnesses in South London. Br J Psychiatry, v. 168, p. 612-9, 1996.

MIECZKOWSKI, T. ; BARZELAY, D. ; GROPPER, B. ; WISH, E. Concordance of three measures of cocaine use in an arrestee population: hair, urine and self-report. J Psychoactive Drugs, v. 23(3), p. 241-9, 1991.

MINKOFF, K. An integrated treatment model for dual diagnosis of psychosis and addiction. Hosp Community Psychiatry, v. 40, p. 1031-6, 1989. 
NOORDSY, D. L. ; DRAKE, R. E. ; TEAGUE, G. B. ; OSHER, F. C. ; HURLBUT, S. ; BEAUTEDD, M. S. ; PASKUS, T. S. Subjetive expiriences related to alcohol use among schizophrenics. J Nerv Ment Dis., v. 179, p. 410-4, 1991.

NOTO, A. R. ; GALDUROZ, J. C. F. ; CARLINI, E. A. Maconha: uma avaliação da situação brasileira através de quatro parâmetros epidemiológicos. ABP-APAL, v. 17(4), p. 133-7, 1995.

OSHER, F. C. ; DRAKE, R. E. ; NOORDSY, D. L. Correlates and outcomes of alcohol use disorder among rural outpatients with schizophrenia. J Clin Psychiatry, v. 55, p. 109-13, 1993.

RACBEISEL, J. ; SCOTT, J. ; DIXON, L. Co-occuring severe mental illness and substance use disorders: a review of recent research. Psychitric Services, v. 50(11), p. 1427-34, 1999.

REGIER, D. A. ; FARMER, M. E. ; RAE, D. S. ; MYERS, J. K. ; KRAMER, M. ; ROBINS, L. N. ; GEORGE, L. K. ; KARNO, M. ; LOCKE, B. Z. One-month prevalence of mental disorders in the United States and sociodemographic characteristics: the Epidemiologic Catchment Area study. Acta Psychiatr Scand., v. 88(1), p. 35-47, 1993.

REGIER, D. A. ; BOYD, J. H. ; BURK, J. D. ; RAE, D. S. ; MYERS, J. K. ; KRAMER, M. ; GEORGE, L. K. ; KARNO, M. ; LOCKE, B. Z. Onemonth prevalence of mental disorders in the United States.Based on five Epidemiologic Catchment Area sites. Arch Gen Psychiatry, v. 45, p. 977 86, 1988.

REGIER, D. A. ; FARMER, M. E. ; RAE, D. S. ; LOCKE, B. Z. ; KEITH, S. J. ; JUDD, L. L. ; GOODWIN, F. K. Comorbidity of mental disorders with alcohol and other drug abuse: results from the Epidemiologic Catchment Area (ECA) study. JAMA, v. 264, p. 2511-18, 1990.

RIES, R.; MULLEN, B. A. ; COX, G. Sympton severity and utilization of treatment resources among dualy diagnosed inpatients. Hosp Community Psychiatry, v. 45, p. 562-7, 1994.

ROBINS, L. N. ; WING, J. ; WITTCHEN, H. U. ; HELZER, J. R. ; BABOR, T. F. ; BURKE, J. ; FARMER, A. ; JABLENSKY, A. ; PICKENS, R. ; REGIER, D. A.; SARTORIUS, N. ; TOWLE, L. H. The composite international diagnostic interview: an epidemiologic instrument suitable for use in conjunction with different diagnostic systems and different cultures. Arch Gen Psychiatry, v. 45, p. 1069-77, 1989.

SALlOUM, I. M. ; MOSS, H. B. ; DALEY, D. C. Substance abuse and schizophrenia: impediments to optimal care. Am J Drug Alcohol Abuse, v. 17(3), p. 321-36, 1991. 
SCHEIER, F. R. ; SIRIS, S. G. A review of psychoactive substance use and abuse in schizophrenia: patterns of drug choice. J Nerv Ment Dis., v. 175, p. 641-52, 1987.

SELZER, M. L. The Michigan Alcoholism Screening Test: the quest for a new diagnostic instrument. Am J Psychiatry, v. 127, p. 1653-8, 1971.

SERPER, M. R. ; ALPERT, M. ; RICHARDSON, N. A. ; DICKSON, S. ; ALLEN, M. H. ; WERNER, A. Clinical effects of recent cocaine use on patients with acute schizophrenia. Am J Psychiatry, v. 152, p. 1464-9, 1995.

SHANER, A. ; KHALSA, M. E. ; ROBERTS, L. ; WILKINS, J. ; ANGLIN, D. ; HSIEH, S. C. Unrecognized cocaine use among schizophrenic patients. Am J Psychiatry, v. 150(5), p. 758-62, 1993.

SKINNER, H.A. The Drug Abuse Screening Test. Addictive Behaviours, v. 7, p. 363-71, 1982.

SOYKA, M. ; ALBUS, M. ; KATHMANN, N. ; FINNELI, A. ; HOFSTETTER, S. ; HOLZBACH, R.; IMMLER, B. ; SAND, P. Prevalence of alcohol and drug abuse in schizophrenic inpatients. Eur. Arch. Psychiatric Clin Neurosci., v. 242, p. 326-72, 1993.

STATACORP. Statistical software:release 6.0. College station. Tx Stata Corporation, 1999.

STOCKWELL, T. ; MURPHY, D. ; HODGSON, R. The severity of alcohol dependence questionnarie: its use, reability and validity. Br J Addict., v. 78, p. $145-56,1983$.

SUllivaN, G. ; WELlS, B. K. ; MORGENSTERN, H. ; LEAK, B. Identifying modifiable risk factors for rehospitalization: a case-control study of seriously mentally ill persons in Mississippi. Am J Psychiatry, v. 152, p. 1749-56, 1995.

SWOFFORD, C. D. ; KASCKOW, J. W. ; SCHELLES-GILKEY, G. ; INDERBITZIN, L. B. Substance use: a powerful predictor of relapse in schizophrenia. Schizophrenia Res., v. 20, p. 145-51, 1996.

TESSLER, R. C. ; DENNIS, D. L. A synthesis of NIMII-funded research concerning persons who are homeless and mental ill. NIMH division of education and services system liaison, Washington, 1989.

THORNICROFT, G. ; BREWIN, C. R. ; WING, J. Measuring mental health needs. 1. Ed, Gaskel, Royal College of Psychiatrists, cap. 8, p. 140-60, 1992. 
VERDOUX, H. ; MURY, M. ; BESANCON, G. ; BOURGEOIS, M. Comparative study of substance dependence comorbidity in bipolar, schizophrenic and schizoaffective disorders. Encephale, v. 22(2), p. 95101, 1996.

VESSONI, A. L. N. Adaptação e estudo de confiabilidade da escala de avaliação dos sintomas positivos e negativos para esquizofrenia no Brasil. São Paulo, 1993. Dissertação (mestrado) - Escola Paulista de MedicinaUNIFESP.

WARNER, L.A. ; KESSLER, R.C. ; HUGHES, M. ; ANTHONY, J.C. ; NELSON, C.B. Prevalence and correlates of drug use and dependence in the United States. Results from the National Comorbidity Survey. Arch Gen Psychiatry, v. 52(3), p. 219-29, 1995.

WORLD HEALTH ORGANIZATION. Life Chart Rating Form. WHO, Geneva, 1992.

WORLD HEALTH ORGANIZATION. Psychiatric Disability Assessment Schedule (WHO/DAS). WHO, Geneva, 1988.

WORLD HEALTH ORGANIZATION. Schedules of clinical assessment in neuropsychiatry SCAN. WHO, Geneva, 1996.

WORLD HEALTH ORGANIZATION. The ICD-10 Classification of mental and behavioural disorders. Clinical descriptions and diagnostic guidelines. WHO, Geneva, 1992.

YESAVAGE, J. A. ; ZARCONE, V. History of drug abuse and dangerous behaviour in inpatient schizophrenics. J Clin Psychiatry, v. 44, p. 259-61, 1983. 


\section{APÊNDICES}

APÊNDICE 1

Nome do paciente:

ID

Entrevistador:

Data da entrevista: $\ldots$

Data de nascimento:

Gênero: (1) homem (2) mulher

Naturalidade: cidade Estado

Há quantos anos em São Paulo?

Escolaridade (codifique): (1) $1^{\circ}$ grau

(2) $2^{\circ}$ grau

(3) superior

(4) pós graduação

Qual o último ano de escolaridade completado?

Estado civil (codifique): (1) solteiro

(2) casado

(3) viúvo

(4) separado/divorciado

(5) amasiado 
APÊNDICE 2

\section{PANSS}

NOME:

ID

ENTREVISTADOR:

1- Delírios

P2- Desorganização Conceitual 1

P3- Comportamento Alucinatório 1

P4- Excitação

P5- Grandeza

P6- Desconfiança

P7- Hostilidade

N1- Afetividade Embotada

N2- Retraimento Emocional

N3- Contato Pobre

N4- Retraimento Social Passivo/Apático

N5- Dificuldade no Pensamento Abstrato

N6- Falta de Espontaneidade e Fluência

N7- Pensamento Estereotipado

G1- Preocupação Somática

G2- Ansiedade

G3- Sentimento de Culpa

G4- Tensão

G5- Maneirismos/Posturas

G6- Depressão

G7- Retardo Motor

G8- Falta de Cooperação

G9- Conteúdo Incomum do Pensamento

G10- Desorientação

G11- Déficit de Atenção

G12- Falta de Julgamento e "Insight"

G13- Ambivalência Volitiva

G14- Pobreza no Controle dos Impulsos

G15- Preocupação

G16- Esquiva Social Ativa
Data da Entrevista:

$\begin{array}{lll}1 & 2 & 3 \\ 2 & 3 & 4 \\ 2 & 3 & 4 \\ 1 & 2 & 3 \\ 1 & 2 & 3 \\ 2 & 3 & 4 \\ 2 & 3 & 4\end{array}$

7

7

7

7

7

$\begin{array}{lllllll}1 & 2 & 3 & 4 & 5 & 6 & 7\end{array}$

7

7

$\begin{array}{lllllll}1 & 2 & 3 & 4 & 5 & 6 & 7 \\ 1 & 2 & 3 & 4 & 5 & 6 & 7\end{array}$

\begin{tabular}{|c|c|c|c|c|c|c|}
\hline 1 & 2 & 3 & 4 & 5 & 6 & 7 \\
\hline & 1 & 2 & 3 & 4 & 5 & 6 \\
\hline 1 & 2 & 3 & 4 & 5 & 6 & 7 \\
\hline 1 & 2 & 3 & 4 & 5 & 6 & 7 \\
\hline & 1 & 2 & 3 & 4 & 5 & 6 \\
\hline & 1 & 2 & 3 & 4 & 5 & 6 \\
\hline 1 & 2 & 3 & 4 & 5 & 6 & 7 \\
\hline & 1 & 2 & 3 & 4 & 5 & 6 \\
\hline 1 & 2 & 3 & 4 & 5 & 6 & 7 \\
\hline & 1 & 2 & 3 & 4 & 5 & 6 \\
\hline
\end{tabular}

$\begin{array}{lllllll}1 & 2 & 3 & 4 & 5 & 6 & 7\end{array}$

$\begin{array}{lllllll}1 & 2 & 3 & 4 & 5 & 6 & 7\end{array}$

$\begin{array}{llll}4 & 5 & 6 & 7\end{array}$

$\begin{array}{llllllll}1 & 2 & 3 & 4 & 5 & 6 & 7\end{array}$

$\begin{array}{lllllll}1 & 2 & 3 & 4 & 5 & 6 & 7 \\ 2 & 3 & 4 & 5 & 6 & 7 & \end{array}$

$\begin{array}{lllllll}1 & 2 & 3 & 4 & 5 & 6 & 7\end{array}$

$\begin{array}{lllllll}1 & 2 & 3 & 4 & 5 & 6 & 7\end{array}$ 


\section{APÊNDICE 3}

\section{WHO PSYCHIATRIC DISABILITY ASSESSMENT SCHEDULE (WHO/DAS)}

\section{Seção 1: Comportamento global}

1.1 Cuidados pessoais

a) higiene pessoal

b) hábitos alimentares

c) manutenção da moradia ( p. ex, manter o próprio quarto arrumado)

1.2 Diminuição das atividades

tempo dispendido durante o dia, no que o contexto cultural considera, "não fazendo nada", p. ex, ficar deitado e acordado na cama, ou sentado sem ocupação.

1.3 Lentificação

velocidade do movimento global e agilidade ne execução das atividades diárias

1.4 Isolamento social

(a) esquiva ativa a interação com pessoas

(b) esquiva ativa de estar na presença de outras pessoas

\section{Seção 2: Performance do papel social}

2.1 Participação nas atividades domésticas

a) participação do paciente nas atividades domésticas comuns, como comer junto as outras pessoas, fazer trabalhos domésticos, assistir televisão

b) participação nas decisões sobre a casa ( p. ex, com as crianças, ou dinheiro)

2.2 Papel no casamento: relação afetiva para esposo/a

a) comunicação com o/a esposo/a (p. ex, conversar sobre eventos comuns)

b) habilidade em demonstrar afeição e carinho

c) sentimento do esposo/a de que o paciente seja fonte de suporte para qual possa se voltar

2.3 Papel no casamento: relações sexuais com esposo/a

a) ocorrência de relação sexual

b) se o paciente tem satisfação com as relações sexuais

c) se o/a esposo/a tem satisfação com as relações sexuais

2.4 Papel paterno/materno: interesse e cuidado com as crianças 

a) dedicação e performance no cuidado da criança, de acordo com a posição do paciente na casa ( $\mathrm{p}$. ex, alimentação, colocar na cama, levar a escola)
b) interesse na criança

2.5 Papel sexual: relações com outras pessoas que não um parceiro conjugal ( pacientes solteiros ou que não morem com o/a esposo/a)
a) interesse heterossexual ( ou homossexual) e reações emocionais apresentadas
b) relações atuais ou contatos buscados pelo paciente (independente se há ou não relações sexuais envolvidas

\subsection{Contatos sociais:}

Considerar comportamentos claros de conflito do paciente envolvendo argumentos inapropriados, aborrecimentos, raiva ou marcada irritabilidade aparecendo em situações sociais fora de casa

2.7 Papel ocupacional: performance no trabalho, incluindo estudantes e pessoas em emprego abrigado

a) como o paciente se enquadra à rotina de trabalho, horários, regras

b) qualidade de performance e produção

2.8 Papel ocupacional: interesse em conseguir emprego ou voltar ao trabalho ou estudos

a) interesse em obter ou retornar ao trabalho e estudos

b) medidas tomadas para obter um emprego ou iniciar estudos

\subsection{Interesse em informações}

a) interesse mostrado pelo paciente em eventos locais ou mundiais, ou outros assuntos proporcionais a seu nível social, educacional e inteligência

b) esforços para obter tal informação

2.10 Comportamento do apciente em emergências ou situações fora do comum, que tenha ocorrido nos últimos seis meses
a) doença ou acidente envolvendo membro da familia
b) doença, acidente ou incidente envovendo outras pessoas
c) emergências menores (p. ex, quebra de equipamento)
d) qualquer outra situação fora da rotina para o paciente que normalmente requeira ação

Todos os itens das seções devem ser codificados:

$$
\begin{aligned}
& 0=\text { sem disfunção } \\
& 1=\text { disfunção mínima } \\
& 2=\text { disfunção óbvia } \\
& 3=\text { disfunção séria } \\
& 4=\text { disfunção muito séria }
\end{aligned}
$$




$$
5 \text { = disfunção máxima }
$$

\section{Seção 5: Avaliação Global}

Considerando todas as informações obtidas e codificadas nesta lista, qual a avaliação geral do ajustamento social atual deste paciente?

$$
\begin{aligned}
& 0=\text { excelente ou ajustamento muito bom } \\
& 1 \text { = ajustamento bom } \\
& 2 \text { = ajustamento razoável } \\
& 3 \text { = ajustamento pobre } \\
& 4=\text { desajustamento grave } \\
& 5=\text { desajustamento máximo } \\
& 8=\text { impossível atribuir pontuação }
\end{aligned}
$$




\section{APÊNDICE 4 \\ SCAN \\ USO DE ÁLCOOL}

11.1. Abstenção ao longo da vida

11.2. Freqüência do uso de álcool no último ano e ao longo da vida

11.3. Estimativa da quantidade habitual diária de álcool, no último ano

11.4. Maior uso diário de álcool, em gramas (doses-padrão)

11.5. Freqüência de uso mais intenso de álcool

11.6. Uso de álcool mais recente

11.7. Necessidade subjetiva de álcool

11.8. Incapacidade de se abster ou parar de beber

11.9. incapacidade de parar de beber depois que começou

11.10. Problemas sociais por causa do álcool

11.11. Problemas legais devido ao álcool

11.12. Persistir bebendo mesmo com prejuízo social e/ou legal

11.13. Falência de cumprir as obrigações básicas

11.14. Comportamentos de risco sob o efeito de álcool

11.15. Importância de atividades relacionadas ao beber álcool

11.16. Tempo envolvido em atividades relacionadas à bebida

11.17. Estreitamento do padrão de consumo de álcool

11.18. Tolerância ao álcool

11.19. Problemas psicológicos e de saúde mental devido ao uso do álcool

11.20. Problemas psicológicos e de saúde mental devido ao uso do álcool

11.21. Início dos problemas de saúde mental induzidos pelo álcool

11.22. Interferência devido a sintomas induzidos pelo álcool

11.23. Beber persistente após prejuízo mental

11.24. Problemas de saúde física devido a bebida

11.25. Beber persistente após dano físico

11.26. Problemas de abstinência ao álcool

11.27. Beber para aliviar ou evitar sintomas de abstinência

11.28. Reações patológicas/idiossincráticas ao álcool

11.29. Efeitos tóxicos agudos do álcool, sem complicações

11.30. Trauma, ferimento corporal devido ao álcool

11.31. Hematêmese. Aspiração. Outras complicações

11.32. Alteração da consciência ou anormalidades da percepção provocadas pelo álcool

11.33. Beber atual e passado

11.34. Idade do início da dependência do álcool 
11.35. Idade do fím da dependência do álcool

11.36. Idade do início de danos devido ao álcool.

11.37. Idade ao fim do período de danos devido ao álcool.

11.38. Interferência nas atividades devido ao álcool

\section{USO DE SUBSTÂNCIAS PSICOATIVAS ALÉM DO ÁLCOOL}

12.1. Abstenção de drogas por toda a vida

12.2. Opióides prescritos

12.3. Sedativos, hipnóticos, ansiolíticos prescritos

12.4. Estimulantes prescritos

12.5. Uso de drogas fora da ou sem prescrição

12.6. Freqüência do uso de opióides (1) sem prescrição

12.7. Cannabinóides (2)

12.8. Sedativos, hipnóticos, ansiolíticos (3)

12.9. Cocaína (4)

12.10. Estimulantes (5)

12.11. Alucinógenos (6)

12.12. ECSTASY (7)

12.13. Substâncias voláteis (8)

12.14. Outras e desconhecidas (9)

12.15. Uso mais recente (1-9)

12.16. Pela boca

12.17. Você alguma vez já usou alguma destas [drogas], injetando-as na veia?

12.18. Injetando-as sob a pele ou no músculo?

12.19. Fumando?

12.20. Cheirando ou aspirando?

12.21. Outro método?

12.22. Necessidade subjetiva da droga

12.23. Incapacidade de se abster ou diminuir o uso de droga

12.24. Incapacidade de parar a droga depois que começou

12.25. Problemas sociais devido ao uso de drogas

12.26. Problemas legais devido ao uso de drogas

12.27. Persistir usando drogas mesmo com dano social ou legal

12.28. Incapacidade de cumprir com as obrigações cotidianas básicas

12.29. Comportamentos de risco sob o efeito de drogas [Use exemplo ]

12.30. Importância de atividades relacionadas ao uso de droga

12.31. Tempo gasto em atividades relacionadas à droga 
12.32. Estreitamento do padrão de uso da droga

12.33. Tolerância a drogas

12.34. Problemas de saúde mental devido a drogas

12.35. Início de problemas de saúde mental induzidos por droga

12.36. Interferência devido a sintomas induzidos pela droga

12.37. Uso persistente da droga apesar de prejuízo mental

12.38. Problemas de saúde física relacionados a drogas

12.39. Uso persistente da droga após prejuízo físico

12.40. Abstinência a droga

12.41. Problemas de abstinência por múltiplas drogas

12.42. Usar droga para aliviar efeitos da abstinência

12.43. Efeitos tóxicos das drogas

12.44. Uso atual e uso passado de drogas

12.45. Idade de início da dependência a droga

12.46. Idade do fim da dependência a droga

12.47. Idade de início do período de dano ou abuso pelo uso de drogas

12.48. Idade do fim do período de dano pelo uso de drogas

12.49. Interferência com atividades relacionadas com o uso da droga 


\section{ESTUDO DE PROBLEMAS PSIQUIÁTRICOS E USO DE ÁLCOOL E OUTRAS SUBSTÂNCIAS}

Caro(a) $\operatorname{Sr}(a)$.

Somos pesquisadores da FACULDADE DE MEDICINA - USP, e estamos fazendo um estudo sobre pessoas que tem ou tiveram problemas psiquiátricos. Esse estudo será muito importante para entender melhor se o uso de álcool e outras substâncias interfere nos problemas psiquiátricos, e pode ajudar a melhorar os tratamentos existentes até agora.

Para fazer esse estudo, estamos entrevistando pessoas que passaram em consulta psiquiátrica em setembro, outubro ou novembro de 1997, para saber como elas estão, e para fazer perguntas sobre o uso de álcool ou outras substâncias. Também entrevistaremos um familiar, para perguntar sobre consultas, internações, condições de vida em geral.

Também gostaríamos de entrevistar novamente todas as pessoas daqui a um ano, para saber o que aconteceu nesse período.

Este estudo não interfere no tratamento que você está recebendo, queremos apenas conversar com você e sua família por duas vezes.

Para isso estaremos indo à sua residência no dia , no período da

Caso você não concorde com a entrevista ou prefira trocar o dia e a hora, por favor ligue para os telefones 5087-7011 ou 5087-7012, das 8:00 às 16:00 horas, Segundas ou Terças, ou das 8:00 às 12:00 horas às Quartas, pedindo para falar com Dra. Lilian Ratto. Se for necessário, deixe o recado com um telefone de contato.

Desde já agradecemos muito sua colaboração, até breve.

Dra. Lilian Ratto 